\title{
An Insight into Probiotics Bio-Route: Translocation from the Mother's Gut to the Mammary Gland
}

\author{
Shanmugaprakasham Selvamani ${ }^{1,2}$, Daniel Joe Dailin ${ }^{1,2}$, Vijai Kumar Gupta ${ }^{3}{ }^{\circledR}$, Mohd Wahid ${ }^{4}$, Ho Chin Keat ${ }^{1}$, \\ Khairun Hani Natasya ${ }^{1}$, Roslinda Abd Malek ${ }^{1}$, Shafiul Haque ${ }^{4,5}{ }^{(}$, , R. Z. Sayyed ${ }^{6}{ }^{(}$, Bassam Abomoelak ${ }^{7}$, \\ Dalia Sukmawati ${ }^{8}\left(\mathbb{D}\right.$, Theodoros Varzakas ${ }^{9}$ a and Hesham Ali El Enshasy ${ }^{1,2,10, *(1)}$
}

\section{check for}

updates

Citation: Selvamani, S.; Dailin, D.J.; Gupta, V.K.; Wahid, M.; Keat, H.C.;

Natasya, K.H.; Malek, R.A.; Haque, S.;

Sayyed, R.Z.; Abomoelak, B.; et al. An Insight into Probiotics Bio-Route:

Translocation from the Mother's Gut to the Mammary Gland. Appl. Sci. 2021, 11, 7247. https://doi.org/ 10.3390/app11167247

Academic Editor: Alessandra Durazzo

Received: 25 May 2021

Accepted: 26 July 2021

Published: 6 August 2021

Publisher's Note: MDPI stays neutral with regard to jurisdictional claims in published maps and institutional affiliations.

Copyright: (c) 2021 by the authors. Licensee MDPI, Basel, Switzerland. This article is an open access article distributed under the terms and conditions of the Creative Commons Attribution (CC BY) license (https:// creativecommons.org/licenses/by/ $4.0 /)$.
1 Institute of Bioproduct Development, Universiti Teknologi Malaysia (UTM), Skudai, Johor Bahru 81310, Malaysia; anazputra@gmail.com (S.S.); jddaniel@utm.my (D.J.D.); jared_ho@live.com (H.C.K.); haninatasya29@gmail.com (K.H.N.); roslinda@ibd.utm.my (R.A.M.)

2 School of Chemical and Energy Engineering, Faculty of Engineering, Universiti Teknologi Malaysia (UTM), Skudai, Johor Bahru 81310, Malaysia

3 Center for Safe and Improved Food \& Biorefining and Advanced Materials Research Center, Scotland's Rural College (SRUC), Kings Building, West Mains Road, Edinburgh EH9 3 JG, UK; vijai.gupta@sruc.ac.uk

4 Research \& Scientific Studies Unit, College of Nursing and Allied Health Sciences, Jazan University, Jazan 45142, Saudi Arabia; wahidbiochem@gmail.com (M.W.); Shafiul.haque@hotmail.com (S.H.)

5 Faculty of Medicine, Bursa Uludağ University, Görükle Campus, Nilüger, Bursa 16059, Turkey

6 Department of Microbiology, P.S.G.V.P. Mandal's, Arts, Science, and Commerce College, Shahada 425409, India; sayyedrz@gmail.com

7 Arnold Palmer Hospital Pediatric Speciality Diagnostic Laboratory, Orlando, FL 32806, USA; Bassam.Abomoelak@orlandohealth.com

8 Department of Biology, Faculty of Mathematics and Natural Sciences, Universitas Negeri Jakarta, Jakarta 13220, Indonesia; Dalia-Sukmawati@unj.ac.id

9 Department Food Science and Technology, University of the Peloponnese (TV), 24100 Kalamata, Greece; t.varzakas@uop.gr

10 City of Scientific Research and Technology Applications (SRTA), New Burg Al Arab 21934, Alexandria, Egypt * Correspondence: henshasy@ibd.utm.my

Abstract: Human breast milk (HBM) is unique in its composition as it is adapted to fulfil the newborns' nutritional requirement and helps in improving the health of newborns. Besides various nutrients, the human milk also contains diverse group of microbiotas. The human milk microbiota has a remarkable impact on the growth and development of a newborn. Additionally, the human milk microbiota enhances the colonization of microbes in the gut of infants. Debates about the origin of HBM microbial flora remain premature and contradictory in some cases. Recent data suggest that the maternal gut microbiota has a major impact on microbial composition, areolar skin, and from the infant's oral cavity. The current review investigates the possible route of microbial transfer from the maternal gut to mammary gland and suggests that it might occur through the entero-mammary pathway. It involves precise selection of probiotic microorganisms from the gut, as the human gut hosts trillions of microorganisms involved in gut homeostasis and other metabolic pathways. Gastrointestinal lymphatic vessels, macrophages, and dendritic cells are shown to play a significant role in the microbial transmission. Furthermore, the role of microbial factors in the development of neonatal immunity and translocation of secretory $\operatorname{IgA}(\mathrm{SIgA})$ cells from the intestinal lumen to GALT and finally to mammary glands via entero-mammary link are discussed.

Keywords: breast milk; microbiome; probiotics; lactic acid bacteria; entero-mammary pathway

\section{Introduction}

Human breast milk (HBM) is the gold standard in care for all infants and children. There are various nutritional and non-nutritional bioactive components in human milk. To ensure survivability and healthy development, their compositions are dynamic and 
gradually altered as the newborn grows [1,2]. Human milk also harbors a unique microbial population that naturally develops from the first breastfeed. Due to its dynamic nature and high heterogeneity, the human milk microbiota is also a complex and variable ecosystem [3]. For many years, human milk was considered sterile, and the presence of microorganisms was considered as a contamination or due to infection such as mastitis. Numerous approaches, both culture-dependent and culture-independent, have revealed the existence of diverse bacterial communities. The bacterial communities include Bifidobacteria, Staphylococci, Streptococci, and other lactic acid bacteria [4-6].

Reports differ regarding the source of human milk microbiota. Their existence in the secreted milk is expected to onset during the third trimester of pregnancy and continue throughout the lactation period [7]. Studies have demonstrated that human milk microbiota continuously supply beneficial bacteria into the newborns' gut environment, contributing to the maturation of the digestive and immune functions of the growing infant [8]. Although human milk microbiota is dominated by skin microflora, the population of the beneficial microbiome in the human milk are similar to the composition of gut microbiota. Probiotic bacterial genera including lactic acid bacteria and Bifidobacteria are expected to originate from the maternal gut environment $[8,9]$. The relationship between the gut and mammary glands was confirmed in animal models [6]. In humans, studies have focused primarily on describing the composition, functions, and factors affecting milk microbiota rather than understanding the origin of milk microbiota from the maternal gut $[8,9]$. To address this question, this review explores the possible bio-routes involved in the translocation of gut origin microbiota into the mammary glands. Macrophages can distinguish between pathogenic and commensal microflora in the gut, and they translocate probiotic strains from maternal gut into the mammary glands [10]. Despite their beneficial nature, the presence of any microbial cells or their antigens in the human blood would be considered as infections, and there must be a specific route for gut microbial translocation-more likely, we termed it the 'microbial bio-route'. In this context, the aim of this study was to discuss the composition of human milk microbiome and potential microbial translocation into the human milk. Furthermore, we also highlighted the factors affecting human milk microbial compositions and their likely effects on human health.

\section{General Features of Human Milk Microbiota}

Breast milk harbors a unique microbial population that varies across countries, ethnicities, or even among communities [11]. In the 1970s, there has been a quick rise in the number of HBM banks in the United States and other European countries for newborns in intensive care units (ICUs). The use of preserved milk raised concerns about the sterility of the milk and hygiene issues of the donors [12,13]. Various microbiological and biochemical analysis were performed on the HBM to check its safety before its availability for the newborns ( $0-2$ months) and infants $(0-1$ year)/babies ( $0-4$ years). These clinical tests eventually rejected the long-standing dogma that considered HBM as a sterile fluid [11]. Currently, powerful cutting-edge technologies in molecular biology research have dramatically outperformed the traditional techniques in the assessment of the HBM microbial quality. Currently used molecular techniques such as pyrosequencing of the DNA have been extensively used to identify the complex microbial population in the HBM. These techniques have proven that the HBM holds a unique microbial niche with outstanding benefits for the infants' growth and development [14]. However, HBM microbiome studies are not completed yet and are still inconclusive. 
As culture-dependent methods have confirmed the presence of several bacteria in the HBM collected from healthy women, HBM sample collections were questioned [15]. Figure 1 shows the global distribution of microbial phyla at their different sites including maternal gut, breast milk, and the infant's oral cavity. The origin of HBM microbiota is still a matter of debate. However, growing evidence suggests that maternal gastrointestinal microbiota and maternal breast skin or the infants' oral microbiota might contribute to the microbial population in human milk $[16,17]$.

\section{Maternal gut microbiota}

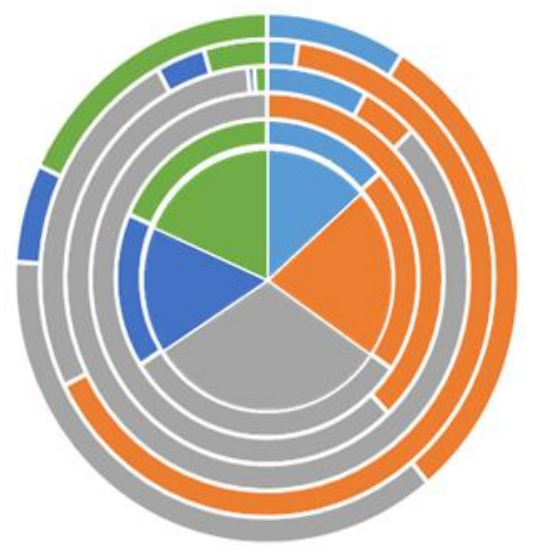

- Actinobacteria
- Bacteriodetes

\section{Human milk microbiota}

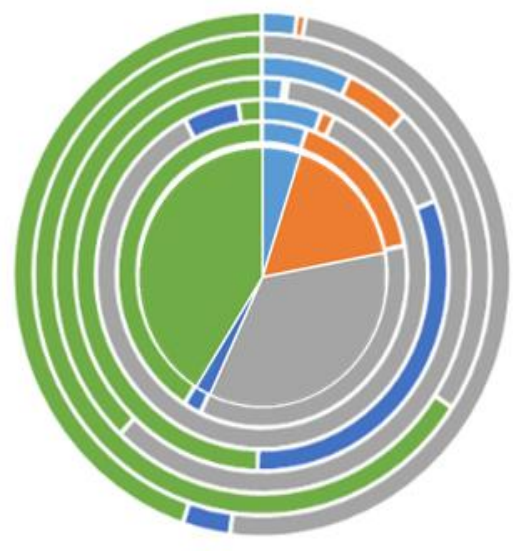

- Firmicutes

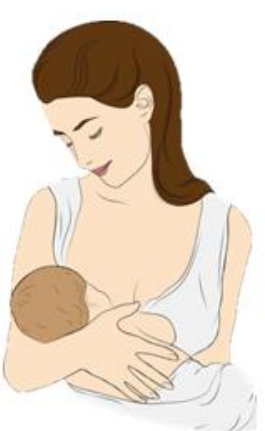

Figure 1. The microbiota composition of the maternal gut, human milk, and infants' oral cavity: a description of relative abundances of essential phyla in each microbiota composition. Concentric cake diagrams schematically represent interindividual variability.

\section{Microbial Partners of Human Milk 'Factory'}

Every breastfed baby receives approximately $10^{4}-10^{6}$ bacterial cells daily, consuming almost $800 \mathrm{~mL}$ of HBM [5,13,18,19]. Most of these microbiotas exist naturally within the HBM, and their diversity is unique. Culture-dependent and -independent techniques have both revealed the diversity of the microbial population present in the HBM $[14,20]$. Relatively, the HMB has a large variability at the intra-individual level, and it undergoes continuous changes over the lactation period [20]. Figure 2 illustrates the most isolated microbial species from the human milk samples. 


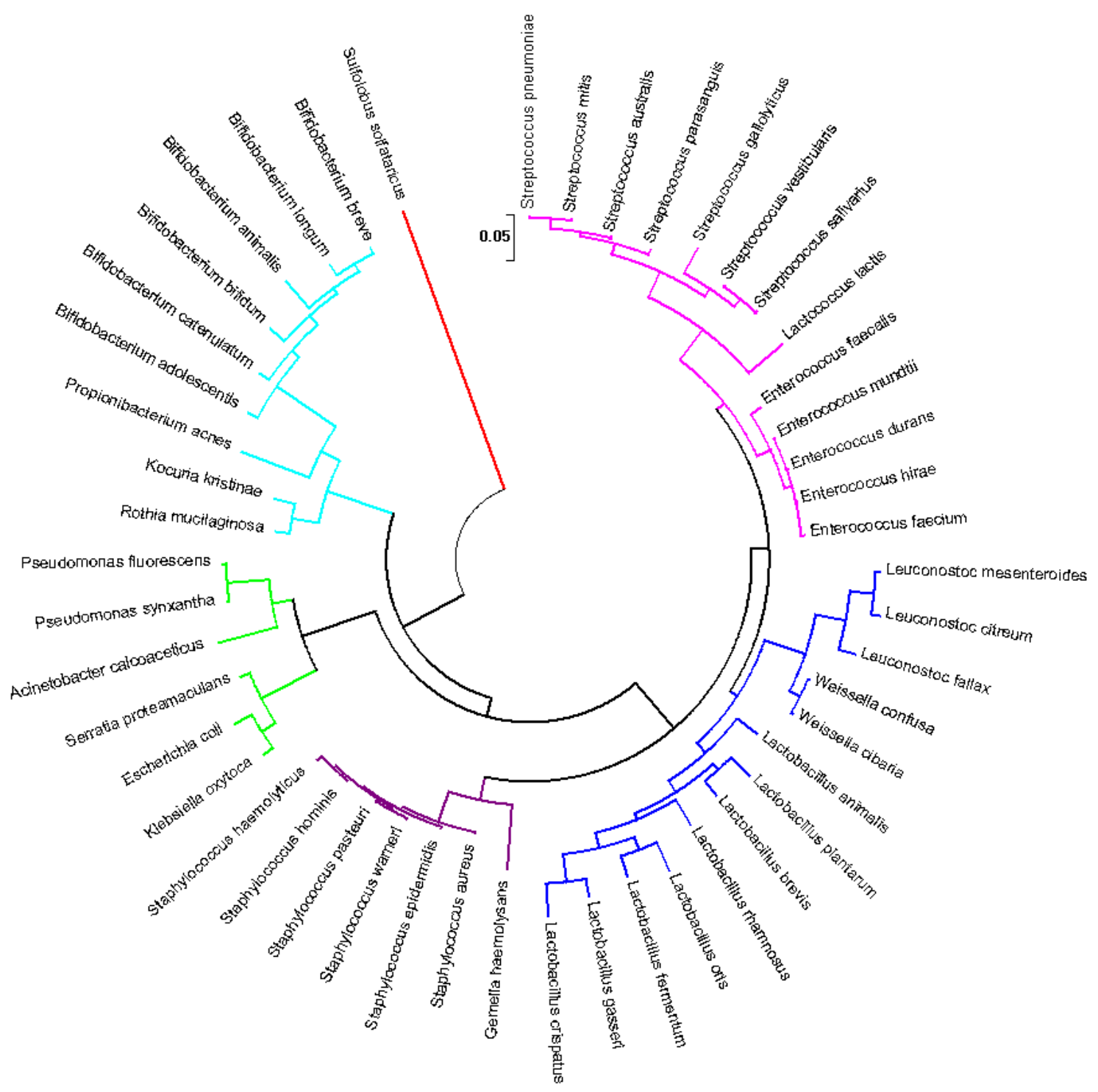

Figure 2. 16S rRNA gene-based phylogenetic tree of the human milk core microbiota. The tree was constructed based on the information provided by Patel et al. [21] and Sakwinska et al. [22] with the inclusion of additional species, of which the genome sequence data have been available since 2015. The analysis involved 49 nucleotide sequences. All the evolutionary analyses were performed by using MEGA (version 7.0). All positions comprising gaps and missing data were removed. The final dataset observed 1266 positions.

\subsection{Predominance of Skin Microflora}

Fitzstevens et al. [14] reported that Staphylococcus and Streptococcus strains were commonly found in almost all culture-independent quantification studies of HMB. The members of Staphylococcus and Streptococcus genera are dominant skin microflora including Propionibacterium, which was also reported to inhabit the infant gut ecosystem. Therefore, their predominance in human milk indicates that they may be derived from maternal skin or from gut microbes [11]. A study revealed that the microbial load in the milk samples of healthy mothers originates from maternal areolar skin. It was predicted that the skin bacteria from the breast surfaces of the nipple or areola could gain access through the ducts of the mammary glands during breastfeeding [23,24].

Still, the question arises here, why does breast milk contain an abundance of opportunistic pathogenic genera such as Staphylococcus and Streptococcus? Traditionally, greater amount of Staphylococcus aureus and Staphylococcus epidermidis in the HBM samples, along 
with other genera including Streptococci and Corynebacterium, were considered as the main agents causing mastitis [25]. Mastitis is a condition of inflammation in lactating mammary glands caused by microbial dysbiosis in the human milk microbiome and leads to opportunistic pathogenic bacteria outgrowth and a decline in healthy and stable commensal bacteria [26]. Opportunistic pathogenic bacteria are the normal microflora that outgrow in numbers due to several conditions including the compromised host's immunity [15]. Patel et al. [21] reported that individuals with subacute mastitis and acute mastitis had higher abundance of Proteobacteria than Firmicutes.

In addition, there have been several studies that reported that commensal skin microflora including Staphylococcus and Streptococcus were also found to be predominant in the breast milk samples collected from healthy mothers [5,20,27]. O'Sullivan et al. [28] reported that skin originated coagulase-negative Staphylococci was able to produce bacteriocin, which inhibits the growth of pathogenic bacteria. In addition, HBM contains various antimicrobial proteins and peptides such as lactoferrin, beta-defensins, and alphadefensin [1,29]. Antimicrobial proteins and peptides present in breast milk show broad inhibitory activity against a variety of pathogens like Streptococcus epidermidis, S. aureus, E. coli, and Streptococcus agalactiae [26].

Previously, Hunt et al. [30] described the survivability of these skin microflorae in human milk. The relative abundance of Staphylococci, especially S. aureus and S. epidermidis strains, was expected due to the influence of human milk oligosaccharides (HMO). The $\mathrm{HMO}$ are well-known for promoting the growth of various commensal bacteria in HBM including Bifidobacterium spp. [31,32]. However, these HMOs were also found to stimulate the growth and proliferation of S. aureus and S. epidermidis strains. Another interesting fact is that these two strains fail to metabolize HMOs available in breast milk [25]. Hence, conjectures can be made that this (above stated reason) could be the main factor for the abundance of skin microflora in the breast milk, especially Staphylococci and Streptococci. After breaching into the mammary glands from the areolar skin, these skin microflorae could be stimulated to multiply by breast milk components. However, the bacterial group survived by utilizing simple sugars rather than competing with the commensal bacteria of the breast milk for HMOs.

Microbiota present naturally in human skin and breast milk plays a crucial role in the immune system's control of a newly born baby. During the breastfeeding process, a significant microbial transmission potential occurs across the areolar skin barriers into the mammary glands [10]. Eventually, this transfer into the infants' gastrointestinal tract will build a neutral microbial ecosystem consisting of beneficial and commensal microorganisms. The introduction of these skin commensals into the infants' gut modulates the innate immunity $[15,30,33-36]$.

\subsection{Human Milk Is a Probiotic Consortium}

Martin and colleagues [37] performed one of the earliest isolations on probiotics from HBM. The study successfully described 78 rod-shaped lactic acid bacterial isolates that grew on MRS medium [37]. The presence of Lactobacillus and Bifidobacterium strains in the human milk has also been confirmed by other studies [38-40]. Sinkiewicz and Ljunggren [38] described the occurrence of Lactobacillus reuteri strains in 220 breast milk samples by the culture-dependent method. Ozgun and Vural [41] characterized 100 presumptive Lactobacillus isolates from colostrum samples by using the API 50 CHL system from BioMeriéux. This study identified several Lactobacillus strains of Lactobacillus brevis, Lactobacillus plantarum, Lactobacillus fermentum, Lactobacillus rhamnosus, and L. reuteri. However, certain lactic acid bacterial isolates share common phenotypes [41]. Soto et al. [42] utilized qualitative PCR analysis, which revealed the presence of Lactobacillus and Bifidobacterial DNA in 160 samples. The most frequently detected Lactobacillus species were L. salivarius, L. fermentum, and L. gasseri. The study also reported the presence of Bifidobacterium breve as the most common Bifidobacterial species [42]. In addition, Biagi et al. [43] also found that the majority of probiotic bacterial OTUs, especially assigned to the Bifidobacterial 
group, were shared between breast milk and stool samples of the same mother-infant pairs. This gives credence to the idea that the mother's milk acts as a source of pioneer probiotic bacteria for the infant's gut microbiota $[33,43]$.

Currently, more Lactobacillus and Bifidobacterium strains have been isolated from human milk to be utilized as potential probiotics [44,45]. Rajoka et al. [46] identified three Lactobacillus strains recently isolated from human milk that exhibited probiotic properties. The study also reported anti-cancer properties in their cell-free culture supernatants. Damaceno et al. [5] characterized three probiotic potential strains, namely L. gasseri; B. breve, and L. salivarius from healthy human milk. These strains agglutinated with different pathogens instead of producing bacitracin. Besides, L. fermentum originating from human milk has been exploited extensively to treat mastitis problems [47]. Several orally administrated probiotic bacteria were also previously isolated from human milk samples [48,49].

Compared to many bacterial groups in mothers' milk, the presence of Lactobacillus and Bifidobacterium spp. has much more beneficial impact on the neonatal immune system [50,51]. In addition, the presence of probiotic strains including Lactobacillus and Bifidobacteria has a protective role where these bacterial strains suppress respiratory and diarrheal infections at the initial infantile age [52,53]. Björkstén et al. [54] reported that infants that have a slower colonization or a lower number of probiotic enterococci and Bifidobacteria may be more vulnerable to gastrointestinal or allergic problems. Other study by Johansson et al. [55] demonstrated that early colonization with Lactobacillus were shown to decrease the effect of allergy. Despite there being no clear protective effect on allergy response reported, breast milk is composed of key players to combat allergy [56,57]. Another recent systematic study demonstrated that the fecal microbiota of infants with colic found that Bifidobacteria and Lactobacilli were greatly decreased in infants with colic compared to the control infants [58]. Furthermore, the colic phenotype was found to be positively associated with various Proteobacteria groups, but negatively associated with bacteria belonging to the Firmicutes phyla, which includes certain lactobacilli and canonical groups that manufacture butyrate and lactate. Interestingly, some studies have found that administering a Lactobacillus strain believed to be from human milk to infants with infantile colic can be beneficial $[58,59]$.

\subsection{Presence of Other Microorganisms}

Besides Proteobacteria and Firmicutes, another common genus found in most of the breast milk samples is Bacteroides. This bacterial genus is generally found in human colostrum. Thus, their presence in HBM might have a vital role in the early establishment of newborn gut microbiota [60]. Bacteroides fragilis can interact with intestinal dendritic cells to stimulate cytokine production. This leads to T-cell proliferation in the lamina propria and promotes physiological expansion of mucosal immunity in neonates $[60,61]$. Another of the most abundant genus detected in healthy breast milk is Acinetobacter [3,22,23]. However, its presence varies greatly in different studies. Sakwinska et al. [56] reported that abundance of Acinetobacter was related to poor aseptic technique during sampling. Patel et al. [21] reported a lower number of Acinetobacter in the breast milk samples collected after sterile cleaning and refusal of foremilk samples.

The presence of fungal strains, especially yeast species in the early development of the infant's gut, was confirmed in human milk [62]. Further information about the naturally existing fungal species in HBM is still lacking. Most of the previous detection has focused on breast candidiasis, the mammary infection by pathogenic Candida species [27,63]. Jiménez et al. [27] confirmed the presence of fungal sequences in a metagenomics analysis on HBM samples collected from mastitis-suffering mothers. Boix-Amorós et al. [64] reported the viable presence of Malassezia, Candida, and Saccharomyces species in the HBM samples from healthy mothers. This was the first evidence to support the natural existence of fungal species in the HBM. In addition, several studies have also described the presence of fungal strains in the milk samples of other mammals $[15,40,65]$. 


\subsection{Predicting the Core of Human Milk Microbiota}

Human milk core microbiota have been estimated by culture-independent techniques $[21,27,30]$. Hunt et al. reported that the core of human milk microbiota consisted of nine bacterial genera. Based on the pyrosequencing technique, various reports have indicated the presence of Streptococcus, Staphylococcus, Serratia, and Corynebacteria as the most abundant genera in human milk, besides Pseudomonas, Ralstonia, Propionibacterium, Sphingomonas, and Bradyrhizobiaceae [30]. In contrast, Jimenez et al. used metagenomics analysis on the milk samples from healthy mothers. Early reports suggest a microbial core composed of seven genera including Staphylococcus, Streptococcus, Bacteroides, Faecalibacterium, Ruminococcus, Lactobacillus, and Propionibacterium [15]. Recently, Williams et al. reported a microbial core of 10 bacterial groups that were abundantly found at each time point throughout six months of postpartum. Streptococcus, Staphylococcus, and Propionibacterium were found in all samples, whereas Pseudomonas, Veillonella, Pilibacter, Gemella, Bacteroides, Prevotella, and Corynebacterium were found in more than $90 \%$ of samples [66]. Meanwhile, Murphy et al. [20] reported a core microbiota consisting of 12 genera including Pseudomonas, Staphylococcus, Streptococcus, Elizabethkingia, Variovorax, Bifidobacterium, Flavobacterium, Lactobacillus, Stenotrophomonas, Brevundimonas, Chryseobacterium, and Enterobacter. This study characterized the bacterial population in breast milk and infant stool collected over the first three months of life, among 10 mother-infant pairs [20].

Therefore, determination of core microbiota in human milk is not easy to standardize due to multiple factors such as geographic locations, milk collection and storage, or analytical methods. Despite these variabilities, the core human milk microbiota is mostly dominated by four bacteria phyla, which are Firmicutes (such as Staphylococcus, Clostridium, Lactobacillus), Actinobacteria (such as Propionibacterium, Corynebacterium), Proteobacteria (such as Pseudomonas, Ralstonia, Sphingomonas, Bradyrhizobiaccea), and Bacteroidetes (such as Prevotella) $[14,15,21,30,66]$. Fitzstevens et al. suggest that this human milk microbial core might vary, but the reported additional genera in several studies are not consistently represented in all of the studies [14]. Furthermore, these milk microbial compositions are dynamic where it changes from highly diverse as lactation progresses $[20,36,60]$.

Recently, it was confirmed that the microbial core in the human milk is not randomly distributed [60]. The microbial composition in the human milk might be due to specific localization. The study performed the first microbial network analysis in the breast milk samples using artificial neural networks (ANNs) to highlight the natural links among variables. Microbial networking enables a new understanding of the interactions existing within a bacterial ecosystem. Microbiome is dynamic and highly heterogeneous, where the role of each member is not often well-defined [67]. As a result, the bacterial network is proving to be a valuable method for deciphering microbial associations and assessing the effect of different interactions with the host. The study will identify the main "hubs", which is represented by the utmost significant member in a bacterial population [60,67]. Drago et al. reported that a streptococci variant, Abiotrophia spp., is an important hub in the microbial network found in colostrum and mature milk from Italian women [68]. This bacterial genus is a common oral cavity microorganism that can also be found in the genitourinary tract and gastrointestinal tract [69]. Thus, the researchers hypothesized that its existence in human milk could be attributed to direct entrance through the mammary ducts while breastfeeding [30] or the entero-mammary pathway [52]. Similarly, the study also found lactic acid bacteria being main hubs for microbial networking in the colostrum from Italian mothers. Furthermore, this analysis showed that mature milk samples had a higher abundance of anaerobic intestinal bacteria than the colostrum samples [68].

\section{Microbial Transmission: Solving the Labyrinth Path}

Diverse hypotheses have been proposed for the common microorganisms between mother and infants. The suggested core microbiota in the human milk is similar to predominant bacterial phyla found in the human body $[60,68]$. 


\subsection{From the Areolar Skin}

Human body skin is a critical interface to protect internal cells from the excessive loss of moisture and entry of microorganisms [70,71]. Colonization of skin microbiota begins from the delivery process [72]. Then, immunotolerance against commensal microorganisms is established during childhood and allows for the sustainability of skin microbiota composition. During adulthood, the skin microbiota develops a balance that is unique to every individual [71,73]. Beyond this individual microbial stability, the human skin microbiota also vary across different bodies due to multiple factors including gender, climate, lifestyle, and maintenance habits $[74,75]$. The four major phyla that have been found in healthy skin were Actinobacteria, Firmicutes, Proteobacteria, and Bacteroides. Among them, Staphylococcus, Propionibacterium, and Corynebacterium were the three predominant genera found in human skin $[70,76]$. Female skin microbiota have been reported as being more diverse than male [73]. The gender differences impact the skin microbial communities due to behavioral characteristics such as the influence of hygiene practices and the use of cosmetics [76]. The greater bacterial diversity on female skin might also be due to the skin $\mathrm{pH}$ where men generally have a more acidic skin [73].

Chan and colleagues have published the first report on the quantification of microbial population on women's nipple and areolar skin [77]. Researchers used the 16S rRNA gene sequencing technique to classify the microbiota found on the nipple surface. Both nipple skin samples from healthy and breast cancer patients showed the presence of Proteobacteria, Firmicutes, and Bacteroides as the predominant genera [77]. However, the study did not correlate identified areolar microorganisms with breast milk or with the infants' gut. Pannaraj et al. demonstrated the first evidence that linked bacterial community in the HBM with areolar skin microbiota [23]. It was found that the newborn received the highest contribution of bacteria from mother's milk and areolar skin during the first month of life and the composition of bacteria received decreased as the infant grew up [23]. The Proteobacteria including Moraxellaceae, Enterobacteriaceae, and Pseudomonadaceae constituted the dominant phylum in the HBM whereas Firmicutes, especially Staphylococcaceae and Streptococcaceae dominated the areolar skin $[23,28]$.

\subsection{Cross-Contamination from Infants' Oral Cavity}

The work done by Pannaraj et al. reported the involvement of areolar skin microbiota in the breast milk [23]. The study also found that about $60 \%$ of infant gut microbiota came from other sources than breast milk and areolar skin. However, the study did not further characterize the sources [23]. One of the possible causes could be translocation from thenewborn oral environment. When an infant is born by the natural method or C-sections it's oral cavity is exposed to the surrounding microbiota [43]. Li et al. reported that oral microbiota differs between infants delivered by natural and C-section [72]. The naturally delivered infants contained an abundance of Lactobacillus, Prevotella and Gardnerella genera than the C-section infants who were more likely to have skin microflora such as Staphylococcus, Pseudomonas, Desulfovibrio, and Petrimonas [68]. Naturally born infants could have placental or vaginal microflora as they might take up some of the amniotic fluid during delivery. This was confirmed with the discovery of various microorganisms found in the meconium (first stool of infants) [78]. Therefore, some of the bacteria from the infants' oral cavity could cross-contaminate and move into the mammary glands during suckling. Biagi et al. found that infants' oral microbiota were the least diverse as Streptococcaceae are the most common with an average relative abundance of 69.8 percent. The study also reported that the baby's mouth microbiota had similar identity between dominant Streptococcus detected in their mothers' milk. This finding suggests that infants' oral microbiota can produce a seeding consequence on the mammary gland microbial community during nursing [43]. However, this factor does not clarify the presence of some bacteria in the pre-colostrum, which are secreted in some women before delivery $[3,37,43]$. 


\subsection{Entero-Mammary Pathway: The 'Silk Route' to Trade Microbiota from Maternal Gut to Infant}

\subsubsection{Link between Maternal Gut and Breast Milk}

The human gastrointestinal environment contains the highest and most diverse microbial population compared to other body parts. Starting from the oral cavity to the rectum, the gastrointestinal tract includes more than 800 species of microflora $[79,80]$. The gut microbiota is generally dominated by Firmicutes and Bacteroidetes phyla where their presence and abundance are crucial in regulating body metabolism and energy harvesting [81,82]. However, the gut microbial population often changes over time with age, besides additional factors such as type of diet, ingestion of alive microorganisms, host genotype, and health status $[80,81]$. The gestation cycle is a structural transition in the female body that includes hormonal, immunological, and metabolic modifications to promote fetal development and growth. During this period, endocrine secretions (especially progesterone and estrogens) are higher and there is major alteration in the immune response [9,79,81]. In addition, there are also noticeable changes in the maternal gut microbiota during pregnancy $[7,83]$.

A healthy gestation period is described with increased bacterial loading and changed gut microbial composition [9]. Koren et al. first reported the gradual change of gut microbiota during early pregnancy [83]. The feces of 91 pregnant women in their first to third trimesters were analyzed by amplifying the V1-V2 variable region of the $16 \mathrm{~S}$ rRNA gene. Microbial composition of first trimester women was similar to healthy nonpregnant women. However, gut microbiota composition evolved dramatically during pregnancy with amplified loads of Actinobacteria and Proteobacteria, but their individual richness was reduced [83]. Similarly, Smid et al. also described that the abundance of maternal gut microbiota was reduced, and their variety and consistency were increased from early pregnancy ( $\leq 20$ weeks) to the end of the third trimester [7]. The changes in gut microbial population over time plays a critical role in normal pregnancy in promoting weight gain, raising maternal metabolic adaptations, and supporting the growth of the fetus $[9,81,83]$. Even after birth, the maternal microbiota does not appear to return to its previous state [83]. As the postpartum period is linked to significant hormonal shifts, it was expected that it could reveal more interesting facts of the hormonal effect on the maternal gut microbiome [9].

Despite the microbial transition before or after postpartum periods, it is an immensely popular fact that maternal gut has a great influence on the breast milk microbiota. Martin et al. performed the earliest comparison on the origin of milk microbiota using random amplification of the polymorphic DNA (RAPD) technique [37]. The RAPD profiles of lactic acid bacteria isolates from breast milk were compared with other isolates collected from various body sites. The study explained that none of the lactic acid bacteria isolates from the breast milk were identical to those from the breast areolar skin surface $[37,84]$. This is also supported by the research done by Soto et al. [42]. The study reported that the presence of skin microflora in the HBM samples seems to be widespread. However, the presence of Lactobacillus and Bifidobacterium must originate from the maternal gastrointestinal environment [42].

Albesharat et al. conducted a study for a large number of isolates by using RAPD and matrix assisted laser desorption ionization-time-of-flight mass spectrometry (MALDITOF-MS) analyses [85]. The researchers found that the RAPD genotypes of L. plantarum, L. fermentum, L. brevis, Enterococcus faecium, Enterococcus faecalis, and P. pentosaceus recovered from breast milk, mothers' guts, and infants' feces were identical [85]. Jost et al. utilized the pyrosequencing technique to reveal vertical sharing of microbiota between maternal gut, breast milk and infant's gut [33]. Despite the predominance of skin microflora, the study also found that gastrointestinal anaerobic bacteria including Bacteroides, Bifidobacterium, Blautia, Clostridium, Collinsella, Parabacteroides, Veillonella, and facultative Lactobacillus spp. were detected in all three ecosystems analyzed. Jost et al. reported that Bacteroides and Bifidobacterium strains had the highest potential for vertical transfer from maternal gut into her breast milk samples [33]. The above-mentioned studies assist the statement that the 
maternal gut bacteria reach the breast milk and colonize the gut of the breast-fed neonate through entero-mammary pathway trafficking $[17,86]$.

However, only certain gut species have been identified from breast milk. Sampling and selective transfer of a specific strain or composition of maternal gut microbiota into the mammary glands remain to be completely explored. Milani et al. performed metagenomics investigation to highlight the transmission of probiotic Bifidobacterial communities as they are important representatives in the intestinal microbiota of infants [86]. With Bifidobacterial ITS profiling coupled with shotgun metagenomics analyses performed in the study, a common Bifidobacterial profile was identified to be similar among the mother-infant pairs. The targeted genome reconstruction from the microbiome also confirmed that these specific Bifidobacterial strains were persistent in the infant gut for six months after birth $[69,86]$. Later, the same group revealed that Bifidobacterial communities are widely spread among mammalian groups that include domesticated animals such as dogs, cats, cows, sheep, goats, horses, and pigs as well as 46 other non-primate mammals including humans and 13 non-human primates [8]. The study reported that the Bifidobacterial strains were found to be transferred from the mother through breast milk. These findings support the hypothesis that probiotics bacteria found in HBM, especially Bifidobacterial strains, are directly acquired from the maternal gut. However, they might be found at very low abundance, and this could be to favor an ultimate transfer to the following generation $[8,17,69,86]$.

\subsubsection{Mucosal Sampling and Migration of Dendritic Cells}

The pathway of transmitting maternal microbiota from the gut to breast milk (enteromammary pathway) can be linked to the improvement of the immunity in newborns $[45,87]$. The mother passes down some of her immunoglobulin (Ig) to the developing fetus to acquire passive immunity during the pregnancy period. IgG is the only antibody that can cross the placental barrier in humans through endosomes within the syncytiotrophoblasts of the placenta $[88,89]$. After giving birth, the maternal immunity is still being successfully transferred and passive immunity is achieved as the lactating mammary glands takes over the functionality of the placenta [89]. Breast-feeding maintains a strong interaction between the mother and her infant by continuing the transfer of maternal immunoglobulin molecules into the newborn.

SIgA is the predominant class of Ig found in HBM and is released by the antibodysecreting cells found in the mammary glands. However, the mammary gland does not seem to stand alone because it is highly influenced by the antibodies produced by the mother in her own gut [90]. During the late pregnancy and lactation stage, the maternal IgA antibody-secreting cells, found in the gut and in the respiratory system, are translocated into the mammary glands [91,92]. The gut mucosal epithelial chemokine CCL28 is the key regulator of the build-up of IgA antibody-secreting cells. The build-up of these cells occurs in the lactating mammary gland. A study using BALB/c mice as the animal model revealed that blocking of CCL28 can lead to significant accumulation of IgA plasma cells in lactating mammary glands [93]. Therefore, the data suggest an internal pathway to transport these antibody-secreting plasma cells from the maternal gastrointestinal tract to her mammary glands, without involving blood circulatory vessels. Furthermore, the translocation is regulated by specific carrier cells [51].

It has been recognized for many years that human lymphatic vessels exhibit a high capacity for accumulating particulate material. The human lymphatic system not only drains the lymph, but is also responsible for moving the immune cells of lymphocytes and antibodies throughout the body to help initiate and participate in an immune response. Several blind ended vessels and fine capillaries of the lymphatic system are found throughout the human body [94,95]. Gut associated lymphoid tissue (GALT) is the main lymphatic present around the gastrointestinal tract (Figure 3) comprising of Peyer's patches, isolated follicles, and mesenteric lymph nodes [94,96]. The GALT serves as antigen sampling and inductive sites of the mucosal immune system. SIgA cells from the gut can adhere selectively to specific M cells found in the intestinal Peyer's patches. This will mediate the translocation 
of the SIgA cells from the intestinal lumen to GALT, and finally to mammary glands via the entero-mammary link [97]. The migration of SIgA cells from the gastrointestinal tract to mammary glands is believed to be under the regulation of hormones such as prolactin, estrogen, and progesterone [98].

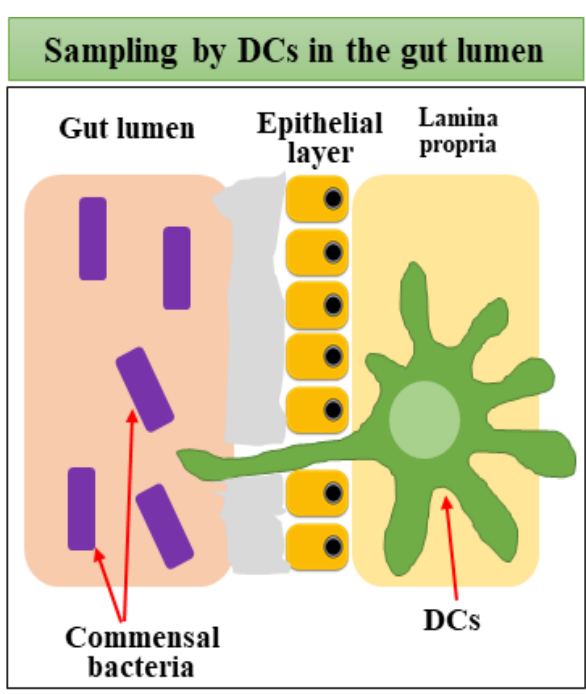

Sampling by $M$ cells and DCs in the Peyer's patch

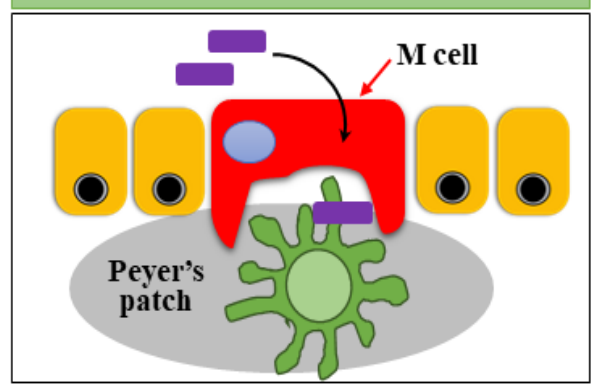

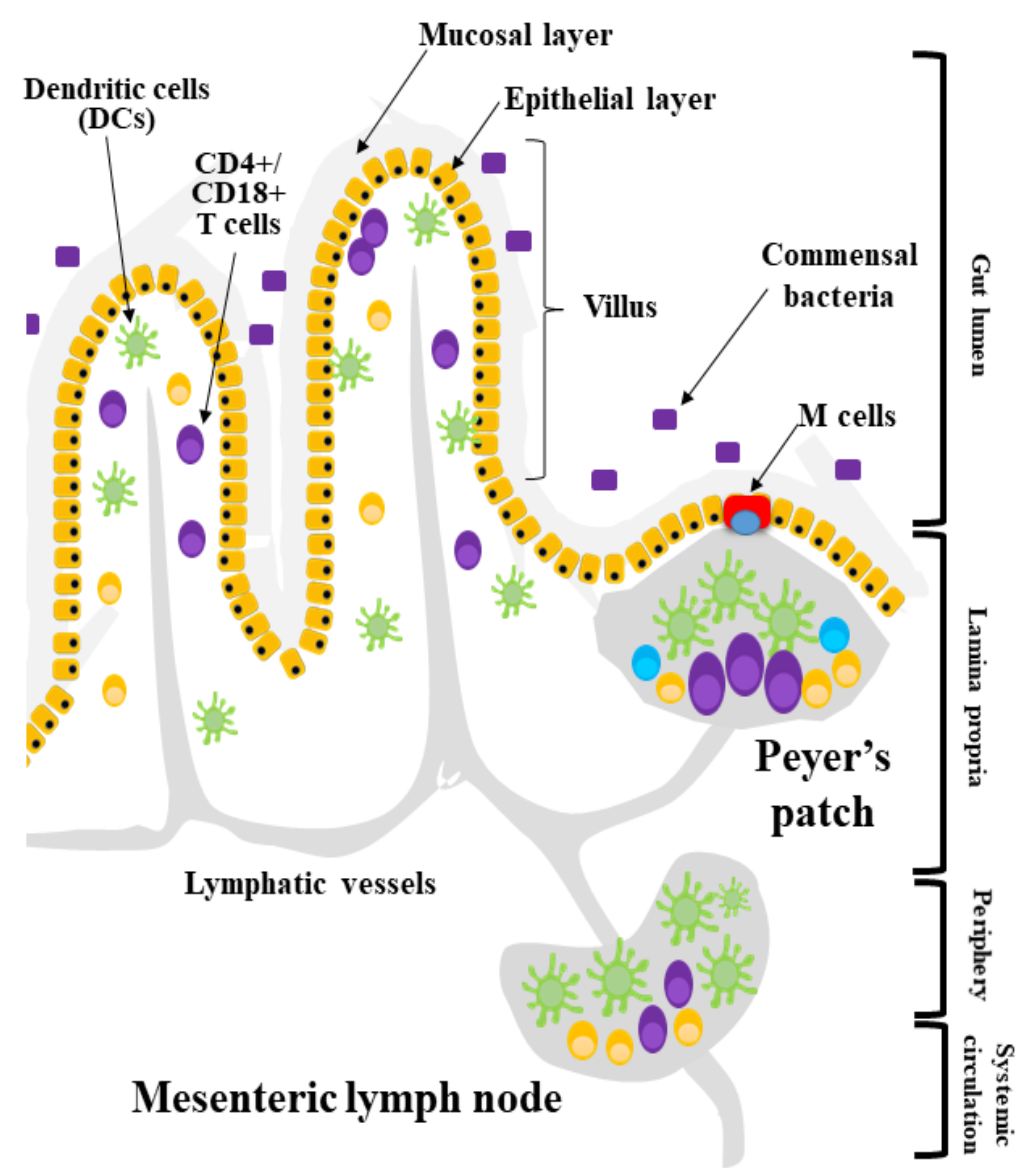

Figure 3. GALT containing lamina propria, Peyer's patches, and mesenteric lymph nodes (MALT). DCs are present in the lymphoid compartments.
Migration of antibody-secreting cells such as SIgA to HBM, originating from the maternal gut, could clearly explain the existence of lymphatic systems and the entero-mammary pathway [91]. However, the sampling and translocation of maternal gut microorganisms into breast milk is best explained by the dendritic cells (DCs). These cells are found throughout many sites including intestinal tissues. DCs actively migrate between the intestinal lamina propria, GALT, Peyer's patches, isolated lymphoid follicles, and in the mesenteric lymph nodes [97,99]. The main function of DCs is to sample antigens found in the intestinal lumen, then migrate into lymphatic nodes and present antigens into $\mathrm{T}$ cells to induce their proliferation and differentiation [99]. Several studies have suggested that DCs such as CD11c+ and CX3CR1+ macrophage cells can extend their trans-epithelial dendrites through the tight junction in the intestinal epithelium to capture luminal antigens or bacteria $[33,99,100]$.

Farache et al. used 2-photon microscopy in live mice to evaluate the microbial sampling by CD103+ DCs in the mesentery lymph nodes [101]. These DCs engulfed Salmonella bacteria in the lamina propria and rapidly retracted toward the soma [101]. The study reported that CD103+ DCs translocated Salmonella bacteria in two steps [102-104]. First, some DCs were found to sense the presence of bacteria and started to secrete chemokines to stimulate more DCs to migrate to the epithelium. Then, the newly arrived DCs extended 
their dendrites toward the lumen by penetrating the tight junction between intestinal cells. The dendrites were extended in response toward the chemokines and started to engulf the bacteria. The DCs will become mature plasma cells when returning to the lamina propria through lymphatic vessels (Figure 3). The presence of antigens on DCs stimulated T cells to initiate adaptive immunity [101,104].

The maternal microbiota are believed to be transferred to the mammary glands by DCs through the above explained lymphatic system and the entero-mammary pathway $[105,106]$. However, the precise selection of microbiota and how DCs differentiate commensal or pathogenic bacteria are yet to be explored. Human gastrointestinal microbiota include a large and diverse community including hundreds of commensal bacteria as well as pathogenic species. The pathogenic microflora induces specific inflammatory responses against commensal microbiota in the competitive environment. Bloom et al. demonstrated that germ-free mice injected with Gram-negative obligate anaerobes originating from the intestinal microbiota consortium would be sufficient to induce spontaneous colitis [107]. The activation of inflammatory responses by the intestinal microflora could mediate subsequent host pattern-recognition receptors [108]. This also leads to the recruitment of specific macrophages and DCs to activate adaptive immune responses [107]. These mononuclear phagocytic cells (macrophages and DCs), which normally reside in the intestinal lamina propria, also play a critical role in preventing inappropriate activation of inflammatory responses to the normal microflora $[107,108]$. But how does the immune system discriminate between commensal and pathogenic bacteria? Several commensal bacteria including Bifidobacteria strains have been found to induce tolerance in monocyte-derived DCs, which can recognize the specific pathogen-associated molecular patterns $[99,108]$. This step could help to precisely discriminate the intestinal microflora. This finding has been utilized to explain DCs translocation of non-pathogenic gastrointestinal bacterial strains like Lactobacillus and Bifidobacterium spp. [10].

We suggest that these translocation patterns could explain the entero-mammary pathway transfer of gut microbiota into mammary glands (Figure 4). DCs sample the commensal bacteria from maternal gut during pregnancy or after birth. After luminal sampling, DCs could travel in the lymphatic systems and reach axial lymphatic nodes. Then, DCs or microbes could migrate to the internal mammary lymphatic node $[39,100,109]$. Bioluminescence imaging was performed by de Andrés et al. to show that lactic acid bacteria could be transported in vivo during pregnancy in mice [6]. In this study, two strains of L. lactis MG1614 and L. salivarius PS2 were genetically modified to harbor luminescent response producing lux operon genes. Both strains could be isolated, and the lux genes were detected by PCR techniques from either milk or mammary gland biopsies after their oral administration to pregnant mice [6]. This clearly proves the existence of an entero-link between the gut and mammary glands involving lymphatic vessels and DCs (Figure 4). We believe that the human lymphatic system is the major path for the translocation of microorganisms in pregnant women. Perez et al. examined the presence of commensal microflora in breast milk and peripheral blood [87]. The study reported that microbial translocation occurred from the intestine to mesenteric lymph nodes and mammary glands during end stages of pregnancy and lactation period in mice [87]. 


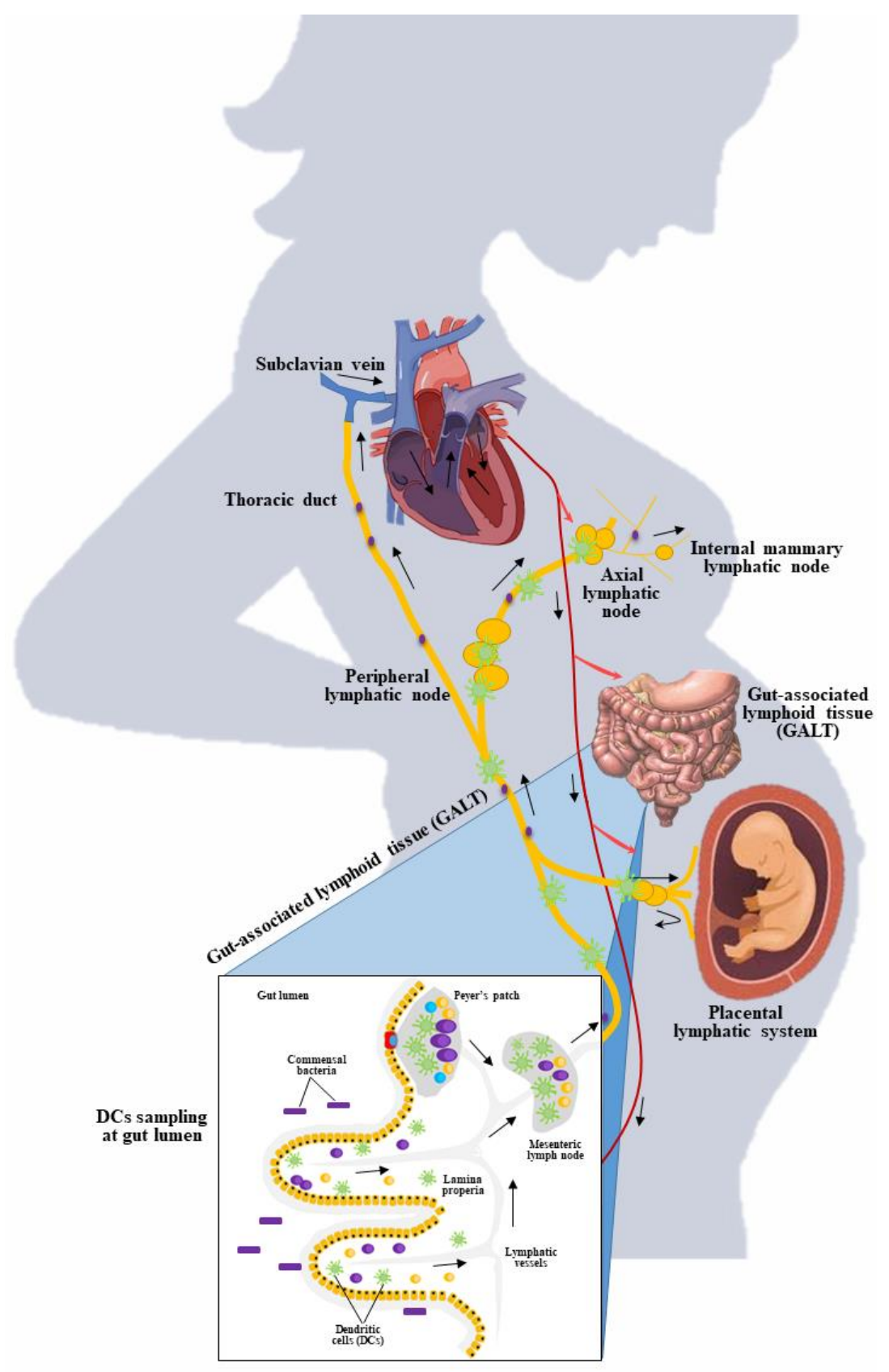

Figure 4. Entero-mammary pathway showing the movement of gut microbial groups into the mammary glands.

\subsubsection{Evidence on Gut Transmission to Breast Milk}

Recently, several reports have shown that orally administrated probiotic microorganisms to pregnant women could also be traced in the breast milk or in the infants' stool (Table 1). These studies have proven the homogeneity of bacterial strains with more precise molecular techniques [48,110-112]. Abrahamsson et al. utilized culture-based techniques and demonstrated that $12 \%$ of women in their probiotic group had viable L. reuteri strains in their colostrum samples compared with $2 \%$ in the placebo group [111]. Similarly, Arroyo et al. reported the presence of L. fermentum CECT5716 and L. salivarius CECT5713 in the milk of mothers who had undergone probiotic treatment for mastitis after 21 days of supplementation [112]. In another small trial, four of 10 women had viable cultures of L. rhamnosus strain LC705 isolated from breast milk samples after supplementation with L. rhamnosus strain LC705 [113]. Additionally, the results of subsequent trials also 
suggested that maternal supplementation with L. fermentum CECT5716 may increase levels of microbial population in the breast milk samples compared to the control and under antibiotic treatments [48].

Table 1. Oral administration of probiotic strains and their respective re-detection methods.

\begin{tabular}{ccc}
\hline References & Oral Administration & Method of Detection \\
\hline Arroyo et al. [112] & L. fermentum CECT5716 & 16s rRNA sequence \\
Nasiraii et al. [113] & L. rhamnosus strain LC705 & qPCR and 16S rRNA sequencing \\
Fernández et al. [52] & L. salivarius PS2 & MALDI-TOF and PFGE \\
Hurtado et al. [48] & L. fermentum CECT5716 & MALDI-TOF mass spectrometry \\
Jiménez et al. [27] & L. salivarius CECT5713 and L. gasseri CECT5714 & species-specific PCR, 16S rRNA sequencing and PFGE \\
\hline
\end{tabular}

The orally administrated bacterial strains detected in breast milk such as L. fermentum CECT5716, L. salivarius CECT5713 [112], or L. rhamnosus strain LC705 [113] were initially isolated from breast milk samples. This could imply the presence of selective sampling and translocation of these bacteria, which have a natural affinity toward breast milk origin bacteria. In this context, translocated bacteria might have specific induction mechanisms to activate DCs [39]. Therefore, the natural gastrointestinal microorganisms or artificially administered probiotic strains are selectively translocated from the maternal gut into mammary glands through the entero-mammary pathway. Because of the small number of mother-infant pairs studied, the biological validity of such results is limited.

GALT lymphoid cells migrate to the mammary gland in humans and rodents, establishing an entero-mammary bond and leading to the so-called "normal mucosal mechanism," in which immune cells migrate between distant mucosal sites. In contrast to these observations, cattle studies have shown that lymphoid cell movement between the gut and the mammary gland is limited, suggesting that the entero-mammary relationship in ruminants is less functional [10]. While most mononuclear phagocytes in breast milk are produced from peripheral blood monocytes, it has recently been hypothesized that a proportion of these mononuclear phagocytes are dendritic cell-like cells that originate in GALT. These cells collect luminal microbiota, and then transport these microbial components to the mammary gland. This pathway teaches the neonatal immune system to recognize commensal-associated bacterial molecular patterns and to react properly to them $[19,83]$.

\subsection{Final Microbial Consortia of Human Milk}

Microbial population in the human milk could be originated from different sources. Based on the core microbiota, it is suggested that the microbiota mainly originate from the maternal digestive tract, breast areolar skin, and from the infants' oral cavity during suckling (Figure 5). The maternal gut bacteria seem to be selectively sampled and these bacteria may reach the mammary glands through an endogenous route of the enteromammary pathway [10]. The gut origin lactic acid bacteria and others were sampled by DCs and arrive to breast tissues and mesenteric lymphatic nodes. The lactic acid bacteria probably form biofilms on the lactiferous tubules of the mammary duct system [91]. Using several developmental stages, the mammary gland trains for lactation [114]. In late pregnancy, the alveolus system of the mammary gland will be maximally grown, and this will provide a favorable environment for the formation of a biofilm. In addition, during the suckling process, the microorganisms from the nipple and areola skin as well as the infants' oral cavity could be mixed in the breast milk produced [23]. However, in healthy women, these common skin microflorae might not breach deep inside the alveolar system. Biofilm formation by Staphylococcus or yeast are often related to the mastitis problem [15]. 


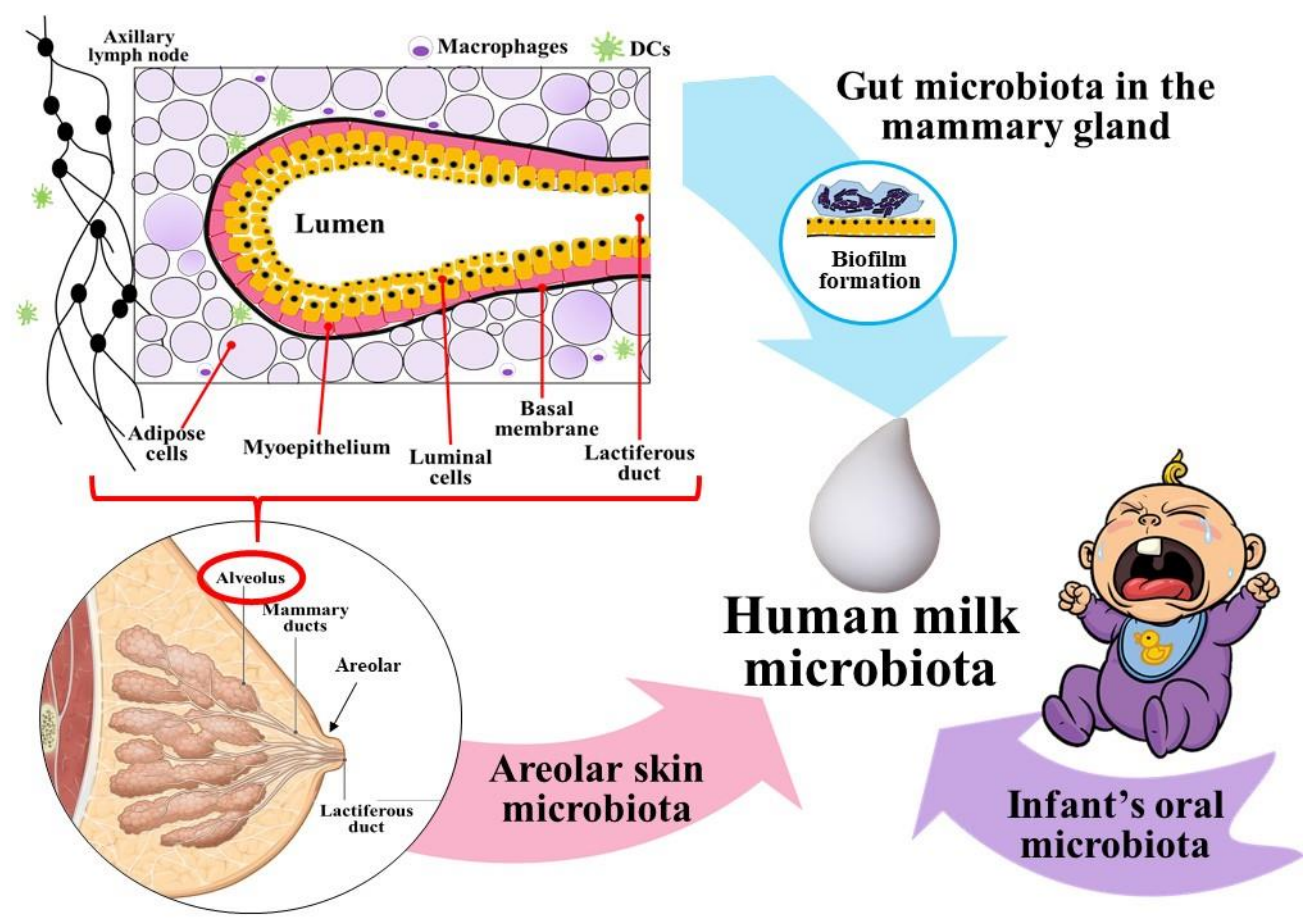

Figure 5. The three possible routes of microbial load in human breast milk.

\section{Factors Affecting Microbial Load in the Breast Milk \\ 5.1. Mode of Delivery}

The method of delivery was one of the reasons that had a significant impact on the microbiota composition of breast milk. There are two types of methods of delivery: caesarean delivery and natural delivery. Caesarean is the delivery through the incisions made in the mother's abdomen and uterus. Toscano et al. [60] explained that the breast milk produced by a mother who delivers naturally has a greater bacterial richness such as commensal and pathogenic microorganisms (ex: Streptococcus and Haemophillus) compared to $\mathrm{C}$-section breast milk microbiota. Thus, $\mathrm{C}$-section and natural delivery have higher abundance of anaerobic bacteria compared to aerobic bacteria. As reported by CabreraRubio et al. [115], mothers who give birth via caesarean delivery have a low amount of Leuconostocaceae and a high amount of Carnobacteriaceae compared with those who give birth by natural delivery. Nevertheless, this finding contradicts the data from a study published by Urbaniak et al. [116], which states that there is no effect on microbial profiles through the mode of delivery.

Another study reported that the differences in the milk produced by both delivery methods emerged from the oral colonization determined by the portal where the newborn exits [116]. Specifically, infants born naturally acquire maternal bacteria from the vaginal environment while maternal skin and breast milk transfer maternal bacteria to infants born through the caesarean method [117]. In addition, work done by Khodayar-Pardo et al. [118] reported that the total concentration of Streptococcus spp. was higher, and concentration of Bifidobacterium spp. was lower in C-section delivery compared to natural delivery. Meanwhile, natural delivery showed a higher correlation between Gammaproteobacteria and Putrescine, but maintained a positive correlation with Pseudomonas fragi [11].

\subsection{Lactation Period}

Breast milk is an infant's first intake of nutrition, and its structure varies from colostrum to mature milk depending on the infant's needs. Breast milk from healthy mother is considered a continuous source of bacteria $[3,115,118,119]$. There are three stages of lactation. Stage I involves secretory initiation, which appears during pregnancy and regulates the development of secretory cells from mammary alveolar cells. At this stage, 
the mammary gland can produce the immunoglobulin-rich mammary secretion known as colostrum. Next, in stage II, the onset of milk secretion, which is known by transition milk. Lactose is the most common milk osmolyte, and an increase in intracellular lactose attracts water into the lactocytes, resulting in a significant increase in milk volume in stage II of lactogenesis. Finally, stage III is mature milk, which shows up one month after delivery and is affected by hormonal signaling, lifestyle, and diet $[115,118,119]$.

Boix-Amorós et al. [3] reported that all three stages of lactation are dominated by Staphylococcus and Acinetobacter genera in colostrum, then, transition milk contained Pseudomonas and Streptococcus, and finally, Acinetobacter was abundant in mature milk. Besides, their bacterial patterns were also composed of other genera including Finegoldia, Streptococcus, Corynebacterium, and Peptoniphlus. The highest bacterial diversity was found in the transition milk with nine genera of bacteria compared to colostrum and mature milk. However, Staphylococcus aureus and epidermis were not detected in samples of healthy mothers [3]. In contrast, in a study published by Li et al., no substantial alteration in the abundance of 17 bacterial families among the samples that had been collected in the three different stages of lactation was detected [36]. The common genera reported in colostrum are Weisella, Leuconostoc, Staphylococcus, Streptococcus and Lactococcus, but the lactic acid genera showed the highest abundance in milk between one and six months after giving birth [115].

Khodayar-Pardo et al. reported that the total counts of Bifidobacterium and Enterococcus increased throughout the lactation period [118]. Total concentration of Bifidobacterium spp. and Enterococcus spp. were lower in colostrum compared to the transition and mature milk. There was a good relationship between colostrum and transition milk as well as transition milk and mature milk [118]. Bifidobacterium spp., Lactobacillus spp., and Staphylococcus spp. showed positive correlation between colostrum and transitional milk. Moreover, Lactobacillus is the most common genus in colostrum and the most abundant throughout the lactation stage. Additionally, Bifidobacterium and Enterococcus counts were greater in colostrum and showed differences in transitional milk and mature milk, which increased throughout the lactation period and depends on the infants' need in each period $[10,120]$.

\subsection{Maternal Nutrition}

Breast milk is a complex biological fluid that contains many nutrients that come from the maternal diet $[1,49]$. Offspring microbiome as well as maternal immunoglobulins and macronutrients will be equally affected by the components of the breast milk [120]. The energy content of breast milk and fat concentration will be affected by the nutritional status of the mother. HBM not only contains diverse microbiota, but is also considered the greatest source of nutrients for the infants' stable growth and development [1,49]. Breast milk proteins also show antimicrobial activities. One of the immunoglobulins known as SIgA aids in fighting the pathogenic bacteria and yeast such as E. coli, V. cholerae, and C. albicans, which can be found in human milk [51]. Breast-fed infants have fewer pathogenic bacteria such as E. coli and Streptococci, but more Lactobacilli and Bifidobacterium whereas formula fed infants had a higher number of enterococci and clostridia [45]. Antimicrobial components in breast milk suppress the growth of potential pathogenic bacteria and activate the progress of beneficial bacteria. Studies showed that antimicrobial compounds such as bacteriocins and hydrogen peroxide from lactic acid bacteria can suppress the growth of various pathogenic bacteria $[37,45,51]$. However, the difference in the physicochemical conditions of the intestinal environment may favor some bacterial growth and suppress the others.

Probiotic, prebiotic, and symbiotic components in the body during prenatal and postnatal periods trigger changes in maternal microbiota [45]. Generally, breast milk generates an environment that aids the growth of Lactobacilli and Bifidobacterium and suppresses pathogenic bacteria [18]. Both bacteria play an important role in reducing the risk of spontaneous preterm delivery and in increasing the serum level erythrocyte glutathione reductase (antioxidant activity) [121]. Besides, Lactobacillus GG (LGG) supplementations raise the cord blood level. They also increase anti-inflammatory cytokines, IFN $\gamma$, and 
TGFb1 in HBM. The perinatal administration of LGG reduces the clinical effects of dermatitis, itching frequency, plasma IgE levels, and elevated levels of IFN $\gamma$ in skin biopsies. The combination of LGG and B. lactis Bb12 ameliorates glucose homeostasis in healthy young females during and after pregnancy. The findings from previous studies show that probiotics supplements play a prominent role in preventing allergy development in both the mother and infant $[29,122,123]$.

Prebiotics such as oligosaccharides introduced into the small intestine of a mother for digestion purposes are responsible for changing the maternal microbiota. O'Sullivan et al. stated that the mass spectrometry-based tool revealed that HMOs support the competitive growth of Bifidobacterium species such as Bifidobacterium longum and B. breve [28]. The combination of prebiotics supplementation of galacto-oligosaccharide (GOS) and fructooligosaccharide also changed the maternal microbiota. Moreover, the increase in bacterial derived metabolites such as inulin and GOS increased the number of bacteria, which synthesize folate. Folates are present in the large intestine for digestion and in blood stream for fetal development. Short chain fatty acids (SCFAs) are another type of metabolite produced by the prebiotics. SCFAs such as acetate, propionate, and butyrate are metabolized in epithelial cells and serve as an energy supply for the mother as well as the developing fetus. SCFAs also regulate the human gamma- to beta-globin gene switching process to produce hemoglobin $[1,121,124]$.

Symbiotic treatment combines probiotics and prebiotics that help combat allergic disorders in children by altering the microbiome of the mother after delivery. They improve the response to Haemophilus influenza type b (Hib) immunization, which increases antibody concentrations responding to diphtheria, tetanus, or Hib. The presence of symbiotic components inside a maternal body stimulates the growth of the delivered probiotic bacteria. It further causes the formation of SCFAs that are anti-pathogenic and immunemodulating agents. The changes occurring in the maternal microbiota by the existence of probiotics, prebiotics, and symbiotic contribute to the offspring's health during early development $[51,125]$.

\subsection{Maternal Health Status}

Maternal health is an important factor contributing to the microbial changes during and after giving birth [126]. The changes in the levels of Bifidobacterium spp. and cytokines correlate with obesity. The increase in Staphylococcus spp., leptin, and proinflammatory fatty acid levels caused by obesity also reduces microbial diversity [127]. In the breast milk of mothers with celiac disease, the levels of cytokines, Bacteroides spp., and Bifidobacterium spp. were reduced [128]. Women diagnosed as HIV-positive had higher bacterial diversity and higher prevalence of Lactobacillus spp. compared to HIV-negative women [129,130]. Obviously, women consume different types of medications, treatments, or antibiotics. Antibiotics reduce the concentration of Bifidobacterium, Staphylococcus, and Eubacterium spp. in milk samples while increasing the incidence of Lactobacillus, Bifidobacterium, and Staphylococcus spp. [16]. Chemotherapy alters maternal microbiota by reducing bacterial diversity as the chemo-drugs kill both beneficial and harmful cells and microorganisms in the body $[16,116]$.

\subsection{Breast Feeding Practices}

The World Health Organization (WHO) strongly recommends exclusive breastfeeding at least for the first six months of life and a continuous breastfeeding for two years or beyond is highly encouraged. However, some babies are unable to feed at the breast due to abnormalities, prematurity, or other illnesses [131]. These babies are fed with expressed milk or pumped milk. During recent years, expressed milk is common in many parts of the world [132]. However, the impact of these indirect breastfeeding practices on the infant's health outcomes is still unknown. A recent study demonstrated that indirect breastfeeding could cause a significant impact on microbial diversity and the composition of human milk [133]. The study reported that the microbial composition of breast milk was differ- 
ent in indirect versus direct breastfeeding and also in manually expressed and pumped milk samples. Higher abundance of opportunistic pathogens such as Stenotrophomonas and Pseudomonas in the pumped milk could pose the risk of infants' respiratory infection asthma [133]. Another study conducted on 393 Canadian mother-infant pairs demonstrated that pumped human milks were enriched with pathogenic microflora and had a lower abundance of bifidobacterial compositions [134]. Both studies suggested that direct contact of the infant's mouth with maternal breast skin is important (Figure 5). The co-occurrence of other microflora is associated with many variables including hygiene, cleanliness of bottles and nipples, type of the pump, milk storage conditions, and duration of storage [133,134]. However, pump-feeding is not recognized as a cause of infant diseases and other health complications. Pump feeding must be acknowledged as this method is the only savior for some mothers, especially those suffering from mastitis. However, pump feeding of breast milk is not similar to direct breast feeding. More studies must be conducted to understand the impact of pumping on milk composition to optimize the process.

\section{Functionality of Human Milk Microbiota}

Because breast milk contains a variety of commensal bacteria, it is considered as a reservoir of bioactive ingredients useful for infants. The microbiota of breast milk contributes to infant wellbeing for its ability to prevent infections, inflammations, allergies, and Enterocolitis.

\subsection{Anti-Infections}

Weisella, Leuconostoc, Staphylococcus, Streptococcus, and Lactococcus are important organisms in colostrum samples. During newborn development, approximately from one to six months, the inhabitants of the oral cavity such as Veillonella, Leptotrichia, and Prevotella increased significantly in the breast milk [115]. These microorganisms also inhibited the growth of E. coli, Salmonella spp., and Listeria monocytogenes [4]. Next, reuterin secreted by L. reuteri is another antimicrobial compound for the colonization of infant gut. L. gasseri CECT5714, L. salivarius CECT5713 and L. fermentum CECT5714 have the capability to inhibit the adhesion of Salmonella cholerasuis to mucins [4,42]. Besides, the growth of pathogen microorganisms such as S. aureus, S. typhimurium, Yersinia enterocolitica, and C. perfringens are controlled by Lactobacilli and Bifidobacteria. The Klebsiella cloacae group have been reported to be frequent gastrointestinal colonizers of neonates [33].

\subsection{Anti-Inflammation}

The microbiota of human milk reduces the inflammatory process, which involves the response of TH2 lymphocytes. L. fermentum CECT5716 and L. salivarius CECT5713 activate the NK cells, activate the CD4and CD8 T cells, and regulatory T cells. Vaccination against diseases such as poliomyelitis, tetanus, and diphtheria improved the immunomodulatory effects of breast milk microbiota in humoral response in breast-fed babies more than formula-fed infants $[4,135]$.

\subsection{Metabolic Functions}

Microbiota of human milk produces different types of metabolites. Lactate-utilizing bacteria in the human milk, namely Eubacterium and Anaerostipes species produce butyrate. Butyrate, being a functional metabolite that plays a crucial role in modulating intestinal function of infant by increasing fecal concentration, fecal moisture, volume, and stool frequency. Other functions of butyrate in early age development include gene expression, cell differentiation, gut tissue development, immune modulation, oxidative stress reduction, and diarrhea control $[83,125]$. 


\subsection{Allergic Prevention}

The intestinal microbiota of a breast-fed infant is predominated by Bifidobacterium. Data showed a significant correlation in Bifidobacterium adolescentis and Bifidobacterium bifidum frequencies and counts in women suffering from allergies [136]. Besides, the amount of Bifidobacterium is lower in allergic mothers when compared to non-allergic mothers. Accordingly, the feces of infants from allergic mothers contain lower amount of Bifidobacterium. Thus, Bifidobacterium in breast milk contributes to allergic prevention in the mother and newborn [136]. Chiu et al. performed an experiment of different strains of Bifidobacterium to determine the potential immunomodulatory strains that can cause human peripheral blood monocular cells to produce cytokines [137]. Data showed that B. adolescentis DB-2458, B. longum subsp. infantis GB-1496, and B. longum HB-762 were the most potential species to induce a high level of IL-10 and TGF-b cytokines.

\subsection{Enterocolitis Prevention}

Some of the bacteria present in breast milk can increase mucin development and decrease intestinal permeability to improve the function of the intestinal barrier [115]. The maternal immune system consists of both secreted and diffused immunoglobulins such as SIgA and IgG. The breast milk contains IgG, SIgA, the most important bacterial pathogen of the neonate, E. coli, specific growth-enhancing lactobacilli, macrophages, and lymphocytes, which prevent the development of enterocolitis in infants $[138,139]$.

\subsection{Growth and Development of Immune System}

The human gut microbiota, which consists of 500 to 1000 microbial species, is also responsible for the enhancement of infant immune system. Most of the fecal population is composed of Bifidobacteria, with smaller numbers of E. coli, Bacteroides, and Clostridia [140]. Infants undergoing caesarean delivery have lower numbers of Bifidobacteria and Bacteroides, whereas they are more often colonized with $C$. difficile. These infants have higher chances of developing atopic disease and prematurity. Many oligosaccharides and glycoconjugates produced by glycosyltransferases in the mammary gland are transferred to human milk and serve as receptors to interfere with the binding of pathogens to epithelial cells. This prevention is necessary to enhance the newborn's immune system through the breast milk $[45,141]$.

\section{Conclusions}

The human milk consists of a dynamic microbial ecology with extraordinary properties and functions. These microorganisms are actively transferred from mother to infant via breast-feeding. The human milk microbiota have been proven to have great impact on the neonatal immune system, optimizing nutrient metabolism, the intestinal barrier function, and enhancing maturation of the digestive tract. These microorganisms enter human milk via several pathways including spreading through the mother's breast skin and movement from the infant's oral cavity and through a special route by the entero-mammary pathway. DCs offer unique microbial translocation mechanisms from the maternal gut into mammary glands. Among the trillions of strains, maternal gut commensal microorganisms are specifically selected and translocated. Several fundamental questions regarding the gut and breast mammary gland axis remain unanswered. The gut-mammary gland axis has a paramount role in the human body system and programming health for life. A precise understanding of the existence of the entero-mammary pathway requires more sophisticated experimental and clinical studies. The growing technology of -omic tools such as metagenomics, transcriptomics, and metabolomics has opened new avenues to identify and understand the existence of specific bacteria in the human milk and the gut. The strainlevel identification of microbiome must also be performed in the bloodstream and within the immune cells involved in the entero-mammary transfer. In conclusion, a comprehensive understanding of the complete scenario of events of such mechanistic pathways will offer novel interventions to improve the health status of newborns. Emerging knowledge offers 
novel opportunities to modulate the gut microbial composition to promote maternalinfant health.

Author Contributions: S.S. and H.A.E.E. conceived the review. S.S., H.C.K., K.H.N., R.A.M., D.S. S.H. and R.Z.S. wrote the manuscript. D.J.D., V.K.G., M.W., B.A., T.V. and H.A.E.E. wrote, edited, and reviewed the manuscript. All authors have read and agreed to the published version of the manuscript.

Funding: S.S. and H.A.E.E. would like to thank RMC, Universiti Teknologi Malaysia (UTM), for financial support from grant no. R.J130000.7609.4C284 and R.J130000.7609.4C240.

Institutional Review Board Statement: Not applicable.

Informed Consent Statement: Not applicable.

Data Availability Statement: Not applicable.

Acknowledgments: S.S. would like to extend this thanks to the School of Postgraduate Studies (SPS), Universiti Teknologi Malaysia (UTM) for the financial support of Zamalah's PhD Scholarship session 2017/2018. S.S. Thanks to Thevarajoo, S. for their technical advice on the construction of a 16S rRNA gene-based phylogenetic tree (Figure 2).

Conflicts of Interest: The authors declare no conflict of interest.

\section{References}

1. Ballard, O.; Morrow, A.L. Human milk composition: Nutrients and bioactive factors. Pediatric Clin. 2013, 60, 49-74.

2. Bardanzellu, F.; Fanos, V.; Strigini, F.A.L.; Artini, P.G.; Peroni, D.G. Human breast milk: Exploring the linking ring among emerging components. Front. Pediatr. 2018, 6, 215. [CrossRef] [PubMed]

3. Boix-Amorós, A.; Collado, M.C.; Mira, A. Relationship between milk microbiota, bacterial load, macronutrients, and human cells during lactation. Front. Microbiol. 2016, 7, 492. [CrossRef] [PubMed]

4. Civardi, E.; Garofoli, F.; Tzialla, C.; Paolillo, P.; Bollani, L.; Stronati, M. Microorganisms in human milk: Lights and shadows. J. Matern. Neonatal Med. 2013, 26, 30-34. [CrossRef]

5. Damaceno, Q.S.; Souza, J.P.; Nicoli, J.R.; Paula, R.L.; Assis, G.B.; Figueiredo, H.; Azevedo, V.; Martins, F.S. Evaluation of potential probiotics isolated from human milk and colostrum. Probiotics Antimicrob. Proteins 2017, 9, 371-379. [CrossRef]

6. De Andrés, J.; Jiménez, E.; Chico-Calero, I.; Fresno, M.; Fernández, L.; Rodríguez, J.M. Physiological translocation of lactic acid bacteria during pregnancy contributes to the composition of the milk microbiota in mice. Nutrients 2017, 10, 14. [CrossRef] [PubMed]

7. Ricks, N.M.; Panzer, A.; McCoy, A.N.; Azcarate-Peril, M.A.; Keku, T.O.; Boggess, K.A.; Smid, M.C. Maternal gut microbiome biodiversity in pregnancy. Am. J. Perinatol. 2018, 35, 024-030. [CrossRef]

8. Milani, C.; Duranti, S.; Bottacini, F.; Casey, E.; Turroni, F.; Mahony, J.; Belzer, C.; Palacio, S.D.; Montes, S.A.; Mancabelli, L.; et al. The first microbial colonizers of the human gut: Composition, activities, and health implications of the infant gut microbiota. Microbiol. Mol. Biol. Rev. 2017, 81, e00036-17. [CrossRef]

9. Nuriel-Ohayon, M.; Neuman, H.; Koren, O. Microbial changes during pregnancy, birth, and infancy. Front. Microbiol. 2016, 7 , 1031. [CrossRef] [PubMed]

10. Rodríguez, J.M. The origin of human milk bacteria: Is there a bacterial entero-mammary pathway during late pregnancy and lactation? Adv. Nutr. 2014, 5, 779-784. [CrossRef] [PubMed]

11. Gómez-Gallego, C.; Kumar, H.; García-Mantrana, I.; du Toit, E.; Suomela, J.-P.; Linderborg, K.M.; Zhang, Y.; Isolauri, E.; Yang, B.; Salminen, S.; et al. Breast milk polyamines and microbiota interactions: Impact of mode of delivery and geographical location. Ann. Nutr. Metab. 2017, 70, 184-190. [CrossRef] [PubMed]

12. Urbaniak, C.; Cummins, J.; Brackstone, M.; Macklaim, J.M.; Gloor, G.; Baban, C.K.; Scott, L.; O’Hanlon, D.M.; Burton, J.; Francis, K.P.; et al. Microbiota of human breast tissue. Appl. Environ. Microbiol. 2014, 80, 3007-3014. [CrossRef] [PubMed]

13. McGuire, M.K.; McGuire, M.A. Got bacteria? The astounding, yet not-so-surprising, microbiome of human milk. Curr. Opin. Biotechnol. 2017, 44, 63-68. [CrossRef]

14. Fitzstevens, J.L.; Smith, K.C.; Hagadorn, J.I.; Caimano, M.J.; Matson, A.P.; Brownell, E.A. Systematic review of the human milk microbiota. Nutr. Clin. Pract. 2016, 32, 354-364. [CrossRef]

15. Jiménez, E.; de Andrés, J.; Manrique, M.; Pareja-Tobes, P.; Tobes, R.; Martínez-Blanch, J.F.; Codoñer, F.M.; Ramón, D.; Fernández, L.; Rodríguez, J.M. Metagenomic analysis of milk of healthy and mastitis-suffering women. J. Hum. Lact. 2015, 31, 406-415. [CrossRef] [PubMed]

16. Urbaniak, C.; McMillan, A.; Angelini, M.; Gloor, G.B.; Sumarah, M.; Burton, J.P.; Reid, G. Effect of chemotherapy on the microbiota and metabolome of human milk, a case report. Microbiome 2014, 2, 24. [CrossRef] [PubMed] 
17. Milani, C.; Mangifesta, M.; Mancabelli, L.; Lugli, G.A.; James, K.; Duranti, S.; Turroni, F.; Ferrario, C.; Ossiprandi, M.C.; van Sinderen, D.; et al. Unveiling bifidobacterial biogeography across the mammalian branch of the tree of life. ISME J. 2017, 11, 2834-2847. [CrossRef]

18. Heikkila, M.P.; Saris, P.E.J. Inhibition of Staphylococcus aureus by the commensal bacteria of human milk. J. Appl. Microbiol. 2003, 95, 471-478. [CrossRef]

19. Ferretti, P.; Pasolli, E.; Tett, A.; Asnicar, F.; Gorfer, V.; Fedi, S.; Armanini, F.; Truong, D.T.; Manara, S.; Zolfo, M.; et al. Mother-toinfant microbial transmission from different body sites shapes the developing infant gut microbiome. Cell Host Microbe 2018, 24, 133-145.e5. [CrossRef]

20. Murphy, K.; Curley, D.; O'Callaghan, T.; O'Shea, C.-A.; Dempsey, E.M.; O'Toole, P.; Ross, R.; Ryan, C.A.; Stanton, C. The composition of human milk and infant faecal microbiota over the first three months of life: A pilot study. Sci. Rep. 2017, 7, 40597. [CrossRef] [PubMed]

21. Patel, S.; Vaidya, Y.H.; Patel, R.; Pandit, R.J.; Joshi, C.G.; Kunjadiya, A.P. Culture independent assessment of human milk microbial community in lactational mastitis. Sci. Rep. 2017, 7, 1-11. [CrossRef]

22. Sakwinska, O.; Moine, D.; Delley, M.; Combremont, S.; Rezzonico, E.; Descombes, P.; Vinyes-Pares, G.; Zhang, Y.; Wang, P.; Thakkar, S.K. Microbiota in breast milk of chinese lactating mothers. PLoS ONE 2016, 11, e0160856. [CrossRef]

23. Pannaraj, P.S.; Li, F.; Cerini, C.; Bender, J.M.; Yang, S.; Rollie, A.; Adisetiyo, H.; Zabih, S.; Lincez, P.J.; Bittinger, K.; et al. Association between breast milk bacterial communities and establishment and development of the infant gut micro-biome. JAMA Pediatrics 2017, 171, 647-654. [CrossRef]

24. Pevzner, M.; Dahan, A. Mastitis while breastfeeding: Prevention, the importance of proper treatment, and potential complications. J. Clin. Med. 2020, 9, 2328. [CrossRef] [PubMed]

25. Hunt, K.M.; Preuss, J.; Nissan, C.; Davlin, C.A.; Williams, J.E.; Shafii, B.; Richardson, A.; McGuire, M.K.; Bode, L. Human milk oligosaccharides promote the growth of Staphylococci. Appl. Environ. Microbiol. 2012, 78, 4763-4770. [CrossRef]

26. Marín, M.; Arroyo, R.; Espinosa-Martos, I.; Fernández, L.; Rodríguez, J. Identification of emerging human mastitis pathogens by MALDI-TOF and assessment of their antibiotic resistance patterns. Front. Microbiol. 2017, 8, 1258. [CrossRef]

27. Jiménez, E.; Arroyo, R.; Cárdenas, N.; Marín, M.; Serrano, P.; Fernández, L.; Rodríguez, J.M. Mammary candidiasis: A medical condition without scientific evidence? PLoS ONE 2017, 12, e0181071. [CrossRef] [PubMed]

28. O'Sullivan, J.N.; Rea, M.C.; O'Connor, P.M.; Hill, C.; Ross, R.P. Human skin microbiota is a rich source of bacteriocin-producing staphylococci that kill human pathogens. FEMS Microbiol. Ecol. 2018, 95, 241. [CrossRef] [PubMed]

29. Lönnerdal, B. Bioactive proteins in human milk: Health, nutrition, and implications for infant formulas. J. Pediatr. 2016, 173, S4-S9. [CrossRef] [PubMed]

30. Hunt, K.M.; Foster, J.; Forney, L.J.; Schütte, U.M.E.; Beck, D.L.; Abdo, Z.; Fox, L.K.; Williams, J.E.; McGuire, M.; McGuire, M.A. Characterization of the diversity and temporal stability of bacterial communities in human milk. PLoS ONE 2011, 6, e21313. [CrossRef] [PubMed]

31. Marcobal, A.; Sonnenburg, J. Human milk oligosaccharide consumption by intestinal microbiota. Clin. Microbiol. Infect. 2012, 18, 12-15. [CrossRef]

32. Thomson, P.; Medina, D.; Garrido, D. Human milk oligosaccharides and infant gut bifidobacteria: Molecular strategies for their utilization. Food Microbiol. 2018, 75, 37-46. [CrossRef]

33. Jost, T.; Lacroix, C.; Braegger, C.P.; Chassard, C. New insights in gut microbiota establishment in healthy breast fed neonates. PLoS ONE 2012, 7, e44595. [CrossRef] [PubMed]

34. Ward, M.; Kariyawasam, V.C.; Mogan, S.B.; Patel, K.V.; Pantelidou, M.; Sobczyńska-Malefora, A.; Porté, F.; Griffin, N.; Anderson, S.H.C.; Harrington, D.J.; et al. Prevalence and risk factors for functional vitamin B12 deficiency in patients with Crohn's disease. Inflamm. Bowel Dis. 2015, 21, 2839-2847. [CrossRef] [PubMed]

35. Rizzatti, G.; Lopetuso, L.R.; Gibiino, G.; Binda, C.; Gasbarrini, A. Proteobacteria: A common factor in human diseases. BioMed Res. Int. 2017, 2017, 1-7. [CrossRef]

36. Li, S.-W.; Watanabe, K.; Hsu, C.-C.; Chao, S.-H.; Yang, Z.-H.; Lin, Y.-J.; Chen, C.-C.; Cao, Y.-M.; Huang, H.-C.; Chang, C.-H.; et al. Bacterial composition and diversity in breast milk samples from mothers living in Taiwan and mainland China. Front. Microbiol. 2017, 8, 965. [CrossRef] [PubMed]

37. Martín, R.; Heilig, H.G.; Zoetendal, E.G.; Jiménez, E.; Fernández, L.; Smidt, H.; Rodríguez, J. Cultivation-independent assessment of the bacterial diversity of breast milk among healthy women. Res. Microbiol. 2007, 158, 31-37. [CrossRef] [PubMed]

38. Sinkiewicz, G.; Ljunggren, L. Occurrence of Lactobacillus reuteri in human breast milk. Microb. Ecol. Health Dis. 2008, 20, 122-126. [CrossRef]

39. Langa, S.; Barragán, A.M.; Delgado, S.; Martin, R.; Martin, V.; Jiménez, E.; Ruíz-Barba, J.L.; Mayo, B.; Connor, R.I.; SuarezFernandez, J.E.; et al. Characterization of Lactobacillus salivarius CECT 5713, a strain isolated from human milk: From genotype to phenotype. Appl. Microbiol. Biotechnol. 2012, 94, 1279-1287. [CrossRef]

40. Martín, R.; Langa, S.; Reviriego, C.; Jiménez, E.; Marín, M.L.; Olivares, M.; Boza, J.; Jiménez, J.; Fernández, L.; Xaus, J.; et al. The commensal microflora of human milk: New perspectives for food bacteriotherapy and probiotics. Trends Food Sci. Technol. 2004, 15, 121-127. [CrossRef]

41. Ozgun, D.; Vural, H.C. Identification of Lactobacillus strains isolated from faecal specimens of babies and human milk colostrum by API 50 CHL system. J. Med. Genet. Genom. 2011, 3, 46-49. 
42. Soto, A.; Martin, V.; Jiménez, E.; Mader, I.; Rodríguez, J.; Fernández, L. Lactobacilli and bifidobacteria in human breast milk: Influence of antibiotherapy and other host and clinical factors. J. Pediatric Gastroenterol. Nutr. 2014, 59, 78. [CrossRef]

43. Biagi, E.; Quercia, S.; Aceti, A.; Beghetti, I.; Rampelli, S.; Turroni, S.; Faldella, G.; Candela, M.; Brigidi, P.; Corvaglia, L. The bacterial ecosystem of mother's milk and infant's mouth and gut. Front. Microbiol. 2017, 8, 1214. [CrossRef] [PubMed]

44. Gomes, A.M.; Malcata, F. Bifidobacterium spp. and Lactobacillus acidophilus: Biological, biochemical, technological and therapeutical properties relevant for use as probiotics. Trends Food Sci. Technol. 1999, 10, 139-157. [CrossRef]

45. Moossavi, S.; Miliku, K.; Sepehri, S.; Khafipour, E.; Azad, M.B. The prebiotic and probiotic properties of human milk: Implications for infant immune development and pediatric asthma. Front. Pediatr. 2018, 6, 197. [CrossRef] [PubMed]

46. Rajoka, M.S.R.; Zhao, H.; Lu, Y.; Lian, Z.; Li, N.; Hussain, N.; Shao, D.; Jin, M.-L.; Li, Q.; Shi, J.L. Anticancer potential against cervix cancer (HeLa) cell line of probiotic Lactobacillus casei and Lactobacillus paracasei strains isolated from human breast milk. Food Funct. 2018, 9, 2705-2715. [CrossRef] [PubMed]

47. Bond, D.M.; Morris, J.M.; Nassar, N. Study protocol: Evaluation of the probiotic Lactobacillus fermentum CECT5716 for the pre-vention of mastitis in breastfeeding women: A randomised controlled trial. BMC Pregnancy Childbirth 2017, 17, 148. [CrossRef] [PubMed]

48. Hurtado, J.A.; Maldonado-Lobón, J.A.; Díaz-Ropero, M.P.; Flores-Rojas, K.; Uberos, J.; Leante, J.L.; Affumicato, L.; Couce, M.L.; Garrido, J.M.; Olivares, M.; et al. Oral administration to nursing women of Lactobacillus fermentum CECT5716 prevents lactational mastitis development: A randomized controlled trial. Breastfeed. Med. 2017, 12, 202-209. [CrossRef]

49. Jeurink, P.; van Bergenhenegouwen, J.; Jiménez, E.; Knippels, L.; Fernández, L.; Garssen, J.; Knol, J.; Rodríguez, J.; Martín, R. Human milk: A source of more life than we imagine. Benef. Microbes 2013, 4, 17-30. [CrossRef]

50. Mueller, N.; Bakacs, E.; Combellick, J.; Grigoryan, Z.; Dominguez-Bello, M.G. The infant microbiome development: Mom matters. Trends Mol. Med. 2015, 21, 109-117. [CrossRef]

51. Cacho, N.T.; Lawrence, R.M. Innate immunity and breast milk. Front. Immunol. 2017, 8, 584. [CrossRef]

52. Fernández, L.; Langa, S.; Martin, V.; Maldonado, A.; Jiménez, E.; Martín, R.; Rodríguez, J.M. The human milk microbiota: Origin and potential roles in health and disease. Pharmacol. Res. 2013, 69, 1-10. [CrossRef]

53. Bergmann, H.; Rodríguez, J.M.; Salminen, S.; Szajewska, H. Probiotics in human milk and probiotic supplementation in infant nutrition: A workshop report. Br. J. Nutr. 2014, 112, 1119-1128. [CrossRef] [PubMed]

54. Björkstén, B.; Sepp, E.; Julge, K.; Voor, T.; Mikelsaar, M. Allergy development and the intestinal microflora during the first year of life. J. Allergy Clin. Immunol. 2001, 108, 516-520. [CrossRef]

55. Johansson, M.A.; Sjögren, Y.M.; Persson, J.-O.; Nilsson, C.; Sverremark-Ekström, E. Early colonization with a group of Lactobacilli decreases the risk for allergy at five years of age despite allergic heredity. PLoS ONE 2011, 6, e23031. [CrossRef] [PubMed]

56. Munblit, D.; Verhasselt, V. Allergy prevention by breastfeeding: Possible mechanisms and evidence from human cohorts. Curr. Opin. Allergy Clin. Immunol. 2016, 16, 427-433. [CrossRef]

57. Van den Elsen, L.W.; Garssen, J.; Burcelin, R.; Verhasselt, V. Shaping the gut microbiota by breastfeeding: The gateway to allergy prevention? Front. Pediatrics 2019, 7, 47. [CrossRef]

58. Sung, V.; D'Amico, F.; Cabana, M.D.; Chau, K.; Koren, G.; Savino, F.; Szajewska, H.; Deshpande, G.; Dupont, C.; Indrio, F.; et al. Lactobacillus reuteri to treat infant colic: A meta-analysis. Pediatrics 2017, 141, e20171811. [CrossRef] [PubMed]

59. Long, B.; Koyfman, A.; Gottlieb, M. Lactobacillus reuteri for treatment of infant colic. Acad. Emerg. Med. 2020, 27, 1059-1060. [CrossRef] [PubMed]

60. Toscano, M.; de Grandi, R.; Grossi, E.; Drago, L. Role of the human breast milk-associated microbiota on the newborns' immune system: A mini review. Front. Microbiol. 2017, 8, 2100. [CrossRef]

61. Olszak, T.; An, D.; Zeissig, S.; Pinilla-Vera, M.; Richter, J.; Franke, A.; Glickman, J.N.; Siebert, R.; Baron, R.M.; Kasper, D.L.; et al. Microbial exposure during early life has persistent effects on natural killer T cell function. Science 2012, 336, 489-493. [CrossRef]

62. Seddik, H.A.; Ceugniez, A.; Bendali, F.; Cudennec, B.; Drider, D. Yeasts isolated from Algerian infants's feces revealed a burden of Candida albicans species, non-albicans Candida species and Saccharomyces cerevisiae. Arch. Microbiol. 2016, 198, 71-81. [CrossRef] [PubMed]

63. Mutschlechner, W.; Karall, D.; Hartmann, C.; Streiter, B.; Baumgartner-Sigl, S.; Orth-Höller, D.; Lass-Flörl, C. Mammary candidiasis: Molecular-based detection of Candida species in human milk samples. Eur. J. Clin. Microbiol. Infect. Dis. 2016, 35, 1309-1313. [CrossRef]

64. Boix-Amorós, A.; Martinez-Costa, C.; Querol, A.; Collado, M.C.; Mira, A. Multiple approaches detect the presence of fungi in human breastmilk samples from healthy mothers. Sci. Rep. 2017, 7, 1-13. [CrossRef] [PubMed]

65. Moossavi, S.; Azad, M.B. Origins of human milk microbiota: New evidence and arising questions. Gut Microbes 2020, 12, 1-10. [CrossRef] [PubMed]

66. Williams, J.E.; Carrothers, J.M.; Lackey, K.A.; Beatty, N.F.; York, M.A.; Brooker, S.L.; Shafii, B.; Price, W.J.; Settles, M.L.; McGuire, M.A.; et al. Human milk microbial community structure is relatively stable and related to variations in macronutrient and micronutrient intakes in healthy lactating women. J. Nutr. 2017, 147, 1739-1748. [CrossRef]

67. Layeghifard, M.; Hwang, D.M.; Guttman, D.S. Disentangling interactions in the microbiome: A network perspective. Trends Microbiol. 2017, 25, 217-228. [CrossRef] 
68. Drago, L.; Toscano, M.; de Grandi, R.; Grossi, E.; Padovani, E.M.; Peroni, D.G. Microbiota network and mathematic microbe mutualism in colostrum and mature milk collected in two different geographic areas: Italy versus Burundi. ISME J. 2017, 11, 875-884. [CrossRef]

69. Duranti, S.; Lugli, G.A.; Mancabelli, L.; Armanini, F.; Turroni, F.; James, K.; Ferretti, P.; Gorfer, V.; Ferrario, C.; Milani, C.; et al. Maternal inheritance of bifidobacterial communities and bifidophages in infants through vertical transmission. Microbiome 2017, 5, 1-13. [CrossRef] [PubMed]

70. Grice, E.A.; Segre, J.A. The skin microbiome. Nat. Rev. Microbiol. 2011, 9, 244-253. [CrossRef] [PubMed]

71. Schommer, N.N.; Gallo, R.L. Structure and function of the human skin microbiome. Trends Microbiol. 2013, 21, 660-668. [CrossRef] [PubMed]

72. Li, H.; Wang, J.; Wu, L.; Luo, J.; Liang, X.; Xiao, B.; Zhu, Y. The impacts of delivery mode on infant's oral microflora. Sci. Rep. 2018, 8, 1-6. [CrossRef] [PubMed]

73. Ying, S.; Zeng, D.-N.; Chi, L.; Tan, Y.; Galzote, C.; Cardona, C.; Lax, S.; Gilbert, J.; Quan, Z.-X. The Influence of age and gender on skin-associated microbial communities in urban and rural human populations. PLoS ONE 2015, 10, e0141842. [CrossRef]

74. Prescott, S.L.; Larcombe, D.-L.; Logan, A.C.; West, C.; Burks, W.; Caraballo, L.; Levin, M.; van Etten, E.; Horwitz, P.; Kozyrskyj, A.; et al. The skin microbiome: Impact of modern environments on skin ecology, barrier integrity, and systemic immune programming. World Allergy Organ. J. 2017, 10, 29. [CrossRef] [PubMed]

75. Szabó, K.; Erdei, L.; Bolla, B.S.; Tax, G.; Bíró, T.; Kemény, L. Factors shaping the composition of the cutaneous microbiota. Br. J. Dermatol. 2017, 176, 344-351. [CrossRef] [PubMed]

76. Ross, A.A.; Müller, K.M.; Weese, J.S.; Neufeld, J.D. Comprehensive skin microbiome analysis reveals the uniqueness of human skin and evidence for phylosymbiosis within the class Mammalia. Proc. Natl. Acad. Sci. USA 2018, 115, E5786-E5795. [CrossRef]

77. Chan, A.A.; Bashir, M.; Rivas, M.N.; Duvall, K.; Sieling, P.A.; Pieber, T.R.; Vaishampayan, P.A.; Love, S.M.; Lee, D.J. Characterization of the microbiome of nipple aspirate fluid of breast cancer survivors. Sci. Rep. 2016, 6, 28061. [CrossRef]

78. Wilczyńska, P.; Skarżyńska, E.; Lisowska-Myjak, B. Meconium microbiome as a new source of information about long-term health and disease: Questions and answers. J. Matern. Fetal Neonatal Med. 2019, 32, 681-686. [CrossRef]

79. Korpela, K.; Costea, P.I.; Coelho, L.P.; Kandels-Lewis, S.; Willemsen, G.; Boomsma, D.I.; Segata, N.; Bork, P. Selective maternal seeding and environment shape the human gut microbiome. Genome Res. 2018, 28, 561-568. [CrossRef]

80. Schmidt, T.; Raes, J.; Bork, P. The human gut microbiome: From association to modulation. Cell 2018, 172, 1198-1215. [CrossRef]

81. Gohir, W.; Whelan, F.J.; Surette, M.G.; Moore, C.; Schertzer, J.D.; Sloboda, D.M. Pregnancy-related changes in the maternal gut microbiota are dependent upon the mother's periconceptional diet. Gut Microbes 2015, 6, 310-320. [CrossRef]

82. Barko, P.; McMichael, M.; Swanson, K.; Williams, D. The gastrointestinal microbiome: A Review. J. Vet. Intern. Med. 2017, 32, 9-25. [CrossRef] [PubMed]

83. Koren, O.; Goodrich, J.K.; Cullender, T.C.; Spor, A.; Laitinen, K.; Bäckhed, H.K.; Gonzalez, A.; Werner, J.J.; Angenent, L.T.; Knight, R.; et al. Host remodeling of the gut microbiome and metabolic changes during pregnancy. Cell 2012, 150, 470-480. [CrossRef]

84. Martín, R.; Langella, P. Emerging health concepts in the probiotics field: Streamlining the definitions. Front. Microbiol. 2019, 10, 1047. [CrossRef] [PubMed]

85. Albesharat, R.; Ehrmann, M.A.; Korakli, M.; Yazaji, S.; Vogel, R.F. Phenotypic and genotypic analyses of lactic acid bacteria in local fermented food, breast milk and faeces of mothers and their babies. Syst. Appl. Microbiol. 2011, 34, 148-155. [CrossRef] [PubMed]

86. Milani, C.; Mancabelli, L.; Lugli, G.A.; Duranti, S.; Turroni, F.; Ferrario, C.; Mangifesta, M.; Viappiani, A.; Ferretti, P.; Gorfer, V.; et al. Exploring vertical transmission of bifidobacteria from mother to child. Appl. Environ. Microbiol. 2015, 81, 7078-7087. [CrossRef]

87. Perez, P.F.; Doré, J.; Leclerc, M.; Levenez, F.; Benyacoub, J.; Serrant, P.; Segura-Roggero, I.; Schiffrin, E.J.; Donnet-Hughes, A. bacterial imprinting of the neonatal immune system: Lessons from maternal cells? Pediatrics 2007, 119, e724-e732. [CrossRef]

88. Palmeira, P.; Quinello, C.; Silveira-Lessa, A.L.; Zago, C.A.; Carneiro-Sampaio, M. IgG placental transfer in healthy and pathological pregnancies. Clin. Dev. Immunol. 2011, 2012, 1-13. [CrossRef]

89. Nagendran, V.; Emmanuel, N.; Bansal, A.S. Does the maternal serum IgG level during pregnancy in primary antibody deficiency influence the IgG level in the newborn? Case Rep. Immunol. 2015, 2015, 1-4. [CrossRef]

90. Brandtzaeg, P. Mucosal immunity: Integration between mother and the breast-fed infant. Vaccine 2003, 21, 3382-3388. [CrossRef]

91. Brandtzaeg, P. The mucosal immune system and its integration with the mammary glands. J. Pediatr. 2010, 156, S8-S15. [CrossRef]

92. Rodríguez, J.; Fernández, L.; Verhasselt, V. The gut-breast axis: Programming health for life. Nutrients 2021, 13, 606. [CrossRef] [PubMed]

93. Wilson, E.; Butcher, E.C. CCL28 controls immunoglobulin (Ig)A plasma cell accumulation in the lactating mammary gland and IgA antibody transfer to the neonate. J. Exp. Med. 2004, 200, 805-809. [CrossRef]

94. Rahman, M.; Mohammed, S. Breast cancer metastasis and the lymphatic system. Oncol. Lett. 2015, 10, 1233-1239. [CrossRef]

95. Suami, H.; Pan, W.-R.; Taylor, G.I. Historical review of breast lymphatic studies. Clin. Anat. 2009, 22, 531-536. [CrossRef]

96. Adlerberth, I.; Wold, A.E. Establishment of the gut microbiota in Western infants. Acta Paediatr. Int. J. Paediatr. 2009, 98, 229-238. [CrossRef] [PubMed]

97. Gutzeit, C.; Magri, G.; Cerutti, A. Intestinal IgA production and its role in host-microbe interaction. Immunol. Rev. 2014, 260, 76-85. [CrossRef] [PubMed] 
98. Worbs, T.; Hammerschmidt, S.I.; Förster, R. Dendritic cell migration in health and disease. Nat. Rev. Immunol. 2016, 17, 30-48. [CrossRef]

99. Aliberti, J. Immunity and tolerance induced by intestinal mucosal dendritic cells. Mediat. Inflamm. 2016, 2016, 1-8. [CrossRef]

100. Martín-Fontecha, A.; Lanzavecchia, A.; Sallusto, F. Dendritic cell migration to peripheral lymph nodes. Organotypic Models Drug Dev. 2008, 188, 31-49. [CrossRef]

101. Farache, J.; Koren, I.; Milo, I.; Gurevich, I.; Kim, K.-W.; Zigmond, E.; Furtado, G.C.; Lira, S.A.; Shakhar, G. Luminal bacteria recruit CD103+ dendritic cells into the intestinal epithelium to sample bacterial antigens for presentation. Immunity 2013, 38, 581-595. [CrossRef] [PubMed]

102. Griffin, A.J.; McSorley, S.J. Development of protective immunity to Salmonella, a mucosal pathogen with a systemic agenda. Mucosal Immunol. 2011, 4, 371-382. [CrossRef] [PubMed]

103. Knoop, K.; Newberry, R.D. Goblet cells: Multifaceted players in immunity at mucosal surfaces. Mucosal Immunol. 2018, 11, 1551-1557. [CrossRef]

104. Bekiaris, V.; Persson, E.K.; Agace, W.W. Intestinal dendritic cells in the regulation of mucosal immunity. Immunol. Rev. 2014, 260, 86-101. [CrossRef] [PubMed]

105. Kordy, K.; Gaufin, T.; Mwangi, M.; Li, F.; Cerini, C.; Lee, D.J.; Adisetiyo, H.; Woodward, C.; Pannaraj, P.S.; Tobin, N.H.; et al. Contributions to human breast milk microbiome and enteromammary transfer of Bifidobacterium breve. PLoS ONE 2020, 15, e0219633. [CrossRef]

106. Rescigno, M.; Urbano, M.; Valzasina, B.; Francolini, M.; Rotta, G.; Bonasio, R.; Granucci, F.; Kraehenbuhl, J.-P.; Ricciardi-Castagnoli, P. Dendritic cells express tight junction proteins and penetrate gut epithelial monolayers to sample bacteria. Nat. Immunol. 2001, 2, 361-367. [CrossRef] [PubMed]

107. Bloom, S.; Bijanki, V.; Nava, G.; Sun, L.; Malvin, N.P.; Donermeyer, D.L.; Dunne, W.M.; Allen, P.M.; Stappenbeck, T.S. Commensal bacteroides species induce colitis in host-genotype-specific fashion in a mouse model of inflammatory bowel disease. Cell Host Microbe 2011, 9, 390-403. [CrossRef]

108. Franchi, L.; Kamada, N.; Nakamura, Y.; Burberry, A.; Kuffa, P.; Suzuki, S.; Shaw, M.H.; Kim, Y.-G.; Núñez, G. NLRC4-driven production of IL-1 $\beta$ discriminates between pathogenic and commensal bacteria and promotes host intestinal defense. Nat. Immunol. 2012, 13, 449-456. [CrossRef]

109. Wendland, M.; Willenzon, S.; Kocks, J.; Davalos-Misslitz, A.C.; Hammerschmidt, S.I.; Schumann, K.; Kremmer, E.; Sixt, M.; Hoffmeyer, A.; Pabst, O.; et al. Lymph node T cell homeostasis relies on steady state homing of dendritic cells. Immunity 2011, 35, 945-957. [CrossRef]

110. Elias, J.; Bozzo, P.; Einarson, A. Are probiotics safe for use during pregnancy and lactation? Canadian family physician. Can. Fam. Physician 2011, 57, 299-301.

111. Abrahamsson, T.R.; Sinkiewicz, G.; Jakobsson, T.; Fredrikson, M.; Björkstén, B. Probiotic Lactobacilli in breast milk and infant stool in relation to oral intake during the first year of life. J. Pediatr. Gastroenterol. Nutr. 2009, 49, 349-354. [CrossRef]

112. Arroyo, R.; Martin, V.; Maldonado, A.; Jiménez, E.; Fernández, L.; Rodríguez, J. Treatment of Infectious mastitis during lactation: Antibiotics versus oral administration of Lactobacilli isolated from breast milk. Clin. Infect. Dis. 2010, 50, 1551-1558. [CrossRef]

113. Nasiraii, L.R. Investigation of lactobacilli from mother's breast milk who were placed on probiotic diet. Afr. J. Microbiol. Res. 2011, 5, 1581-1585. [CrossRef]

114. Macias, H.; Hinck, L. Mammary gland development. Wiley Interdiscip. Rev. Dev. Biol. 2012, 1, 533-557. [CrossRef] [PubMed]

115. Cabrera-Rubio, R.; Collado, M.C.; Laitinen, K.; Salminen, S.; Isolauri, E.; Miras, A.D.; Jackson, R.N.; Jackson, S.N.; Goldstone, A.P.; Olbers, T.; et al. The human milk microbiome changes over lactation and is shaped by maternal weight and mode of delivery. Am. J. Clin. Nutr. 2012, 96, 544-551. [CrossRef]

116. Urbaniak, C.; Angelini, M.; Gloor, G.B.; Reid, G. Human milk microbiota profiles in relation to birthing method, gestation and infant gender. Microbiome 2016, 4, 1-9. [CrossRef]

117. Hoashi, M.; Meche, L.; Mahal, L.; Bakacs, E.; Nardella, D.; Naftolin, F.; Bar-Yam, N.; Dominguez-Bello, M.G. Human milk bacterial and glycosylation patterns differ by delivery mode. Reprod. Sci. 2015, 23, 902-907. [CrossRef]

118. Khodayarpardo, P.; Pascual, L.M.; Collado, M.C.; Martinez-Costa, C. Impact of lactation stage, gestational age and mode of delivery on breast milk microbiota. J. Perinatol. 2014, 34, 599-605. [CrossRef] [PubMed]

119. Nommsen-Rivers, L.A.; Chantry, C.J.; Peerson, J.M.; Cohen, R.J.; Dewey, K.G.; Appleton, K.M.; Rogers, P.J.; Ness, A.R. Delayed onset of lactogenesis among first-time mothers is related to maternal obesity and factors associated with ineffective breastfeeding. Am. J. Clin. Nutr. 2010, 92, 574-584. [CrossRef]

120. Chu, D.M.; Meyer, K.M.; Prince, A.L.; Aagaard, K.M. Impact of maternal nutrition in pregnancy and lactation on offspring gut microbial composition and function. Gut Microbes 2016, 7, 459-470. [CrossRef]

121. Prescott, S.L.; Wickens, K.; Westcott, L.; Jung, W.; Currie, H.; Black, P.N.; Stanley, T.V.; Mitchell, E.A.; Fitzharris, P.; Siebers, R.; et al. Supplementation with Lactobacillus rhamnosus or Bifidobacterium lactis probiotics in pregnancy increases cord blood interferon- $\gamma$ and breast milk transforming growth factor- $\beta$ and immunoglobin A detection. Clin. Exp. Allergy 2008, 38, 1606-1614. [CrossRef] [PubMed]

122. Licciardi, P.V.; Ismail, I.H.; Balloch, A.; Mui, M.; Hoe, E.; Lamb, K.; Tang, M.L.K. Maternal supplementation with LGG reduces vaccine-specific immune responses in infants at high-risk of developing allergic disease. Front. Immunol. 2013, 4, 381. [CrossRef] [PubMed] 
123. Boyle, R.J.; Ismail, I.H.; Kivivuori, S.; Licciardi, P.V.; Robins-Browne, R.M.; Mah, L.-J.; Axelrad, C.; Moore, S.; Donath, S.; Carlin, J.B.; et al. Lactobacillus GG treatment during pregnancy for the prevention of eczema: A randomized controlled trial. Allergy 2010, 66, 509-516. [CrossRef]

124. Liakopoulou, E.; Blau, C.A.; Li, Q.; Josephson, B.; Wolf, J.A.; Fournarakis, B.; Raisys, V.; Dover, G.; Papayannopoulou, T.; Stamatoyannopoulos, G. Stimulation of fetal hemoglobin production by short chain fatty acids. Blood 1995, 85, 3227-3235. [CrossRef]

125. Wopereis, H.; Sim, K.; Shaw, A.; Warner, J.O.; Knol, J.; Kroll, J.S. Intestinal microbiota in infants at high risk for allergy: Effects of prebiotics and role in eczema development. J. Allergy Clin. Immunol. 2018, 141, 1334-1342.e5. [CrossRef]

126. Le Doare, K.; Holder, B.; Bassett, A.; Pannaraj, P.S. Mother's milk: A purposeful contribution to the development of the infant microbiota and immunity. Front. Immunol. 2018, 9, 361. [CrossRef]

127. Kumar, H.; du Toit, E.; Kulkarni, A.; Aakko, J.; Linderborg, K.M.; Zhang, Y.; Nicol, M.; Isolauri, E.; Yang, B.; Collado, M.C.; et al. Distinct patterns in human milk microbiota and fatty acid profiles across specific geographic locations. Front. Microbiol. 2016, 7, 1619. [CrossRef] [PubMed]

128. Benítez-Páez, A.; Olivares, M.; Szajewska, H.; Pieścik-Lech, M.; Polanco, I.; Castillejo, G.; Nuñez, M.; Ribes-Koninckx, C.; Korponay-Szabó, I.R.; Koletzko, S.; et al. Breast-milk microbiota linked to celiac disease development in children: A pilot study from the prevent cd cohort. Front. Microbiol. 2020, 11, 1335. [CrossRef]

129. Zimmermann, P.; Curtis, N. The effect of antibiotics on the composition of the intestinal microbiota-A systematic review. J. Infect. 2019, 79, 471-489. [CrossRef]

130. Zimmermann, P.; Curtis, N. Breast milk microbiota: A review of the factors that influence composition. J. Infect. 2020, 81, 17-47. [CrossRef] [PubMed]

131. Pang, W.W.; Bernard, J.Y.; Thavamani, G.; Chan, Y.H.; Fok, D.; Soh, S.-E.; Chua, M.C.; Lim, S.B.; Shek, L.P.; Yap, F.; et al. Direct vs. expressed breast milk feeding: Relation to duration of breastfeeding. Nutrients 2017, 9, 547. [CrossRef] [PubMed]

132. Becker, G.E.; Smith, H.A.; Cooney, F. Methods of milk expression for lactating women. Cochrane Database Syst. Rev. 2016, 9 , CD006170. [CrossRef]

133. Moossavi, S.; Sepehri, S.; Robertson, B.; Bode, L.; Goruk, S.; Field, C.; Lix, L.M.; de Souza, R.J.; Becker, A.B.; Mandhane, P.J.; et al. Composition and variation of the human milk microbiota are influenced by maternal and early-life factors. Cell Host Microbe 2019, 25, 324-335.e4. [CrossRef] [PubMed]

134. Azad, M.B. Infant feeding and the developmental origins of chronic disease in the child cohort: Role of human milk bioactives and gut microbiota. Breastfeed. Med. 2019, 14, S-22-S-24. [CrossRef]

135. Fan, P.; Li, L.; Rezaei, A.; Eslamfam, S.; Che, D.; Ma, X. Metabolites of dietary protein and peptides by intestinal microbes and their Impacts on gut. Curr. Protein Pept. Sci. 2015, 16, 646-654. [CrossRef]

136. Grönlund, M.-M.; Gueimonde, M.; Laitinen, K.; Kociubinski, G.; Grönroos, T.; Salminen, S.; Isolauri, E. Maternal breast-milk and intestinal bifidobacteria guide the compositional development of the Bifidobacterium microbiota in infants at risk of allergic disease. Clin. Exp. Allergy 2007, 37, 1764-1772. [CrossRef]

137. Chiu, Y.-H.; Tsai, J.-J.; Lin, S.-L.; Chotirosvakin, C.; Lin, M.-Y. Characterisation of bifidobacteria with immunomodulatory properties isolated from human breast milk. J. Funct. Foods 2014, 7, 700-708. [CrossRef]

138. Nolan, L.S.; Parks, O.B.; Good, M. A review of the immunomodulating components of maternal breast milk and protection against necrotizing enterocolitis. Nutrients 2019, 12, 14. [CrossRef]

139. Altobelli, E.; Angeletti, P.M.; Verrotti, A.; Petrocelli, R. The impact of human milk on necrotizing enterocolitis: A systematic review and meta-analysis. Nutrients 2020, 12, 1322. [CrossRef] [PubMed]

140. Bullen, C.L.; Tearle, P.V.; Willis, A.T. Bifidobacteria in the intestinal tract of infants: An in-vivo study. J. Med. Microbiol. 1976, 9 , 325-333. [CrossRef]

141. Laforest-Lapointe, I.; Arrieta, M.-C. Patterns of early-life gut microbial colonization during human immune development: An ecological perspective. Front. Immunol. 2017, 8, 788. [CrossRef] [PubMed] 